Revised version: MS\#BREA5767

Paola Maroni · Emanuela Matteucci · Alessandro Luzzati · Giuseppe Perrucchini · Paola Bendinelli $\cdot$ Maria Alfonsina Desiderio

\title{
NUCLEAR CO-LOCALIZATION AND FUNCTIONAL INTERACTION OF COX-2 AND HIF-1 $\alpha$ CHARACTERIZE BONE METASTASIS OF HUMAN BREAST CARCINOMA
}

Paola Maroni · Alessandro Luzzati · Giuseppe Perrucchini Istituto Ortopedico Galeazzi-IRCCS Milano-Italy

Emanuela Matteucci · Paola Bendinelli · Maria Alfonsina Desiderio

Dipartimento di Morfologia Umana e Scienze Biomediche "Città Studi”, Università degli Studi di Milano- Milano-Italy

The authors Paola Maroni and Emanuela Matteucci equally contributed to this work.

Correspondence: Dr. Maria Alfonsina Desiderio (Full Professor of General Pathology), Università degli Studi di Milano, Dipartimento Morfologia Umana e Scienze Biomediche“Città Studi", Molecular Pathology Laboratory, via Luigi Mangiagalli, 31-20133 Milano-Italy.

Tel: +39/0250315334; Fax: +39/0250315338; E-mail: a.desiderio@ unimi.it 


\begin{abstract}
The aim of the present paper was to identify nuclear co-localization of COX-2 and HIF-1 $\alpha$ in human-bone metastasis of breast cancer, index of transcriptionally-activated cells and functional for gene expression. In particular, we verified whether hypoxia exerted a direct role on metastasis-gene expression or through $\mathrm{COX}-2$ signaling, due to the relevance for clinical implications to individuate molecular targets for diagnosis and therapy. The experiments were performed in vitro with two metastatic clones, 1833 and MDA-231BO, and the parental MDA-MB231 cells, in vivo (1833xenograft model), and in human-bone metastasis specimens. In 1833 cells in vitro, COX-2 signaling pathway was critical for nuclear HIF-1 $\alpha$-protein expression/translocation, mechanisms determining HIF-1 activity and gene expression. The data were corroborated by immunohistochemistry in human-bone metastasis specimens. COX-2 and HIF-1 $\alpha$ showed wide co-localization in the nucleus, indicative of COX-2-nuclear import in transcriptionally activated metastatic cells and consistent with COX-2-HIF-1 $\alpha$ functional interaction. A network of microenvironmental signals controlled COX-2 induction and HIF-1 activation downstream. In fact, hypoxia through HGF and TGF- $\beta 1$ autoregulatory loops triggered a specific array of transcription factors responsible for COX-2 transactivation. The novelty was that HGF and TGF- $\beta 1$ biological signals were produced by hypoxic metastatic cells and, therefore, the microenvironment seemed to be modified by metastaticcell engraftment in the bone. In agreement, HIF-1 $\alpha$ expression in bone-marrow supportive cells occurred in metastasis-bearing animals. Altogether, the data supported the pre-metastatic-niche theory. Our observations might be useful to design therapies against bone metastasis, by affecting the phenotype changes of metastatic cells occurring at the secondary growth site through COX-2HIF-1 interaction.
\end{abstract}

Keywords bone microenvironment $\cdot$ bone metastasis $\cdot$ breast cancer $\cdot \mathrm{COX}-2 \cdot \mathrm{HIF}-1$ 


\section{Introduction}

Metastasis formation is the worst clinical complication of neoplastic disease, and is the primary cause of mortality in breast carcinoma patients [1]. Notwithstanding the clinical relevance of the metastatic process, the molecular basis of growth advantage, tropism for the secondary site (bones, lungs), and osteolysis are partly known.

We have generated a pre-clinical model of human-osteolytic metastasis using 1833-high bone metastatic clone [2], suitable to study microenvironment involvement in breast-cancer metastasis outgrowth and progression. The 1833-metastasis is characterized by a partial reversion to an epithelial phenotype, compared to the frankly mesenchymal phenotype of the parental MDAMB231 cells. HIF-1 and NF- $k$ B transcription factors drive this revertant phenotype, and are controlled at epigenetic level [3].

The current most recognized theory for metastasis engraftment is the metastatic niche model, presuming that the tumor cell does not solely dictate its own fate but that the formation of a hospitable microenvironment is essential- not just permissive- to enable a disseminating tumor cell to spawn a secondary tumor growth [4]. These niches form as a result of factors secreted by tumor and stroma cells, and can either be newly induced or be adaptations of pre-existing physiological niches, such as stem cell niches of hematopoietic organs $[1,5]$. Thus, the gene signature associated with poor prognosis facilitates the emergence of metastatic cells in the primary tumor, but the specific set of genes associated with bone metastasis seems responsible for the cellular activities necessary for metastatisation [6-8]. For completeness, the metastatic capacity might be considered as a late, acquired event in tumorigenesis and during secondary growth, through epigenetic control of transcription $[9,10]$.

The aim of the present paper is to clarify some molecular mechanisms underlying bone metastasis formation by human-breast carcinoma, taking into account the plasticity of the metastatic phenotype through responsiveness to physical (hypoxia) and biological (hepatocyte growth factor, 
HGF, and transforming growth factor- $\beta 1$, TGF- $\beta 1$ ) stimuli $[2,11]$. To this purpose, we studied specimens of human-bone metastasis of breast cancer and the 1833-xenograft model. The data were confirmed by in vitro experiments using 1833 clone, that permitted to stress the differences with parental MDA-MB231 cells. The functional impact on metastatic phenotype of microenvironmental stimuli was examined through the triggering of a network of transcription factors, and the expression of specific target genes. The rationale of the present study was that a complex array of stimuli forms the metastatic microenvironment, and that it might influence specific sets of genes and thus the metastatic phenotype and the organotropism. Gene expression depends, in fact, on the specificity of the stimulus and the interaction of transcription factors showing consensus sites on the gene promoter. Transcription factors do not work alone but in cooperation. The transcriptional properties of a particular factor are influenced either by its position, relative to other factors bound to a given promoter, or by the abundance of transcriptional cofactors in a given cell type in a certain context [12]. Our study deals with the molecular mechanisms involved in cyclooxygenase-2 (COX2) expression and function in bone metastasis of breast cancer. COX-2 promoter is characterized by consensus sites for various transcription factors [13], but their functional role in bone metastatic process has never been investigated. Moreover, COX-2 intracellular localization might be implicated in the control of the activity of some transcription factors, such as HIF-1- the master regulator of oxygen homeostasis [14]- by controlling the expression and function of the inducible $\alpha$ subunit.

Here, the subcellular localization of COX-2 and the mechanisms responsible for the regulation of its expression/localization were evaluated, in relation to HIF-1 $\alpha$ expression and HIF-1 activity, due to the possible importance for biology, prognosis, therapy and gene-expression pattern of metastasis. HIF-1 $\alpha$ expression in carcinomas is regulated by HIF-1 and NF- $k$ B activities, as demonstrated using Semenza's HIF-1 $\alpha$-promoter constructs [15]. We give for the first time a fairly comprehensive view of the pattern of HIF-1-target genes, under the influence of metastasismicroenvironmental stimuli and after blockade of COX-2 activity or TGF- $\beta 1$-typeI receptor. 
In animal models obtained with mouse (TM40D-MB or 4T1.2) and human (MDA-MB231) cells, COX-2/PGE2 system participates in osteolysis $[6,16-18]$ but the distinct functions contributing to breast-carcinoma metastasis remain largely unknown. HGF/Met couple is important for the cross-talk between metastasis and microenvironment [2], and its activation by hypoxia might be hypothesized based on data from normal and neoplastic cell types [19, 20]. CXCR4 may drive tumor cells to the secondary sites (lymph nodes, bones) where CXCL12 specific ligand is produced [21], but the experimental data on human metastases are still preliminary [22, 23]. Moreover, HIF$1 \alpha$ correlates with Met and metastasis in node-negative breast cancer [24, 25]. HIF-1 $\alpha$ protein is overexpressed in multiple types of human carcinomas, including primary-breast cancer (29\%) as well as in lymph node metastases (69\%) [26].

The adaptability of bone-metastasis phenotype to hypoxic microenvironment at the bonesecondary growth site resulted in unique-molecular events, such as increased HIF-1 $\alpha$ expression and nuclear localization both in the xenograft model and in the human specimens of bone metastasis, possibly orchestrated by COX-2. A fundamental permissive role was played by TGF- $\beta 1$ and HGF, produced by the metastatic cells in the hypoxic bone microenvironment.

\section{Materials and methods}

\section{Reagents}

Recombinant-human HGF and TGF- $\beta 1$, human HGF and TGF- $\beta 1$ immunoassays (ELISA) and anti-human CXCR4(MAB 172) antibody were from R\&D System (Abigdon, United Kingdom).

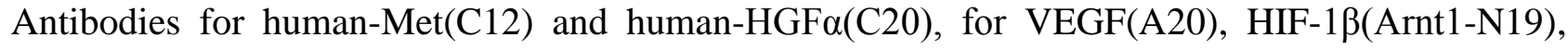
vinculin and B23 were from Santa Cruz Biotechnology (Santa Cruz, CA). Anti-COX-2 antibody was from Cayman Chemical (Ann Arbor, MI). Anti-HIF-1 $\alpha$ antibodies for immunohistochemistry 
(clone $\mathrm{H} 1 \alpha 67$ ) and Western blot (clone54) were from Novus Biological (Littleton, CO) and BDTransduction Laboratories (Franklin Lakes, NJ). Anti-cytokeratin(Pan) clone-AE1/AE3 was from Zymed Laboratories Inc (San Francisco, CA). Alexa Fluor488 and 568 antibodies were from Molecular Probes (Eugene, OR, USA). N-[2-(cyclohexyloxy)-4-nitrophenyl]-methanesulfonamide (NS398) and 4-[4-(1,3-benzodioxol-5-yl)-5-(2-pyridinyl)-1H-imidazol-2-yl]-benzamide hydrate (SB431542) were from Sigma-Aldrich (St Louis, MO). SN50 was from Alexis. CGP049090 was kindly given by Novartis (Basel, Switzerland).

Cells and Xenograft Model

Parental MDA-MB231 cells, the derived bone-metastatic clone 1833 wild-type and retrovirally transfected with triple-reporter construct (1833/TGL) were a generous gift of J. Massagué (Memorial Sloan-Kettering Cancer Center, New York). The xenograft model was obtained with 1833/TGL [2]. MDA-231BO were kindly given by T. Yoneda (The University of Texas, San Antonio).

Surgical Specimens

Ten surgical specimens of bone metastasis, originating from breast carcinomas, were from patients who provided informed consent, in accordance with Declaration of Helsinki.

Histology and Immunohystochemistry

Serial sections of fixed and decalcified xenograft-model bone metastasis and human-bone metastasis specimens [2], were probed with anti-COX-2 (1:50) and anti-HIF-1 $\alpha$ (1:1000) overnight at $4^{\circ} \mathrm{C}$. 
Immunofluorescence

The 1833 cells $\left(8 \times 10^{4}\right)$ on coverslips were exposed to (i) 24-h hypoxia [15], in the presence or the absence of $1 \mu \mathrm{M}$ NS398 (COX-2 inhibitor) (4-h inhibitor pre-treatment and 20-h hypoxia plus the inhibitor) [16]; (ii) $100 \mu \mathrm{g} / \mathrm{ml}$ cycloheximide for 2 or $4 \mathrm{~h}$ after 12-hypoxia exposure [27]; (iii) 10 $\mu \mathrm{M}$ clasto-lactacystin- $\beta$-lactone (LLnL) $4 \mathrm{~h}$ before HGF-treatment (24 h) [15]. The antibodies used were: anti-COX-2 (1:30) and anti-HIF-1 $\alpha$ (1:50). The images were collected at X400 magnification under Eclipse 80i, Nikon Fluorescence microscope.

Plasmids and Cell Transfection

The cells were transfected with the construct containing the multimer for Hypoxia-responsive element (6-HRE, pGL3PGK6TKp), NF-kB-binding sites (3-NFkB), TCF-binding sites (6-TCF, TOPFLASH), AP-1-binding sites (4-AP-1) from P.J. Ratcliffe, M. Hung, J. Gottardi and N. Colburn [2, 3], or 5-Ets-1 consensus sequences [10]. The expression vector (200 ng) for HIF-1 $\alpha$ or HIF-1 $\beta$ (L. Poellinger, Karolinska Institute, Stockholm, Sweden) was co-transfected with the genereporters. After overnight starvation ( $0.1 \%$ fetal bovine serum, FBS), 24-h treatment with $200 \mathrm{ng} / \mathrm{ml}$ HGF [2] or $5 \mathrm{ng} / \mathrm{ml}$ TGF- $\beta 1$ [16], also under hypoxia, was performed. Cells exposed to hypoxia alone were not starved. COX-2-reporter plasmid (-1432/+59)Luc or (-327/+59)Luc (S. Wilkinson, Vanderbilt University, Nashville, TN) was co-transfected with expression vectors for the dominant negative of ARNT (corresponding to mutated HIF-1 $\beta$ subunit), Jun (TAM67) or Ets-1 ( $\triangle \mathrm{EBHHB)}$ $[3,10]$, or treated with $50 \mu \mathrm{g} / \mathrm{ml} \mathrm{SN50} \mathrm{(NF-kB}$ inhibitor) or $10 \mu \mathrm{M}$ CGP049090 (TCF-inhibitor) [28, 29]. As internal control, Renilla luciferase plasmid was co-transfected, and Firefly/Renilla luciferase activity ratios were calculated by the software. 


\section{Western Blot Assay}

Total extracts were prepared from cells exposed to $10 \mu \mathrm{M}$ LLnL $4 \mathrm{~h}$ before TGF- $\beta 1$, HGF or hypoxia treatment. Total and nuclear extracts were obtained from cells exposed to TGF- $\beta 1$ or hypoxia also in the presence of $1 \mu \mathrm{M}$ NS398 or $5 \mu \mathrm{M}$ SB431542. For Western blots, total (100 $\mu \mathrm{g})$ and nuclear $(50 / 100 \mu \mathrm{g})$ protein-extracts were used. Antibody dilutions were: anti-HIF-1 $\alpha$ 1:350,

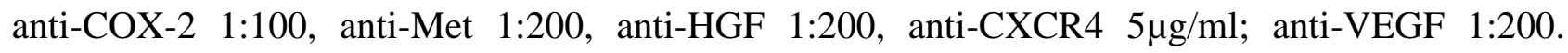
Densitometric analysis was performed after reaction with ECL- or ECL plus-chemiluminescence kit (GE Healthcare, Milan, Italy).

\section{ELISA Assay}

TGF- $\beta 1$ and HGF were measured in conditioned medium of cells exposed to hypoxia for $24 \mathrm{~h}$ in the absence of serum, following manufacturer's protocol.

\section{Statistical Analysis}

Luciferase activities and densitometric values were analyzed by analysis of variance, with $P<0.05$ considered significant. Differences from controls were evaluated on original experimental data. COX-2 half-life was evaluated using densitometric values of Western blot by the least squares method. 


\section{Results}

Involvement of COX-2-signaling pathway in the hypoxic response

Bone is a hypoxic microenvironment capable of potentiating tumor metastatic growth [11]. Previous reports have shown that HIF-1 $\alpha$ overexpression is correlated with distant metastasis and poor prognosis for breast cancer patients, and is more frequently observed in metastases than in primary tumor, suggesting an active role of HIF-1 $\alpha$ in regulating metastatic progression [26]. In addition, HIF-1 $\alpha$ seems to be a promising target for controlling organotropic metastatization of breast cancer [30], and inhibitors of HIF-1 $\alpha$ and TGF- $\beta$ may improve treatment of bone metastases obtained with MDA-MB231 cells increasing patient survival $[6,16,31]$. TGF- $\beta$ and HGF regulate COX-2 expression in breast and colon carcinoma cells, respectively, and hypoxia potentiates HGFdependent $\mathrm{PGE}_{2}$ release in colorectal cancer $[16,32] . \mathrm{PGE}_{2}$ participates in nuclear translocation of exogenously expressed HIF-1 $\alpha$ in prostate carcinoma cells [33]. COX-2 inhibition largely prevents MDA-MB231 bone metastasis by decreasing osteoclast number and increasing apoptosis [16]. Here, we extended and deepened the knowledge on the molecular events of breast cancer metastatization by evaluating the involvement of COX-2-signaling pathway downstream of biological signals (TGF- $\beta 1$ and HGF) in the hypoxic response, and we compared in vivo and in vitro models- using the 1833 bone metastatic clone- and human bone metastasis.

As shown in Fig. 1a, hypoxia increased COX-2 and HIF-1 $\alpha$ fluorescence signals in nuclei of human 1833 cells, index of their co-localization (see merge images), and COX-2 signal also in perinuclear compartment. The treatment with NS398, a COX-2 inhibitor, largely reduced COX-2 expression throughout the cell, and prevented nuclear HIF-1 $\alpha$ translocation. A more quantitative evaluation of HIF-1 $\alpha$ protein was obtained by Western blot (Fig. 1b). HIF-1 $\alpha$-protein level increased (about 4-fold) in hypoxic-1833 cells, and NS398 almost completely blocked this 
stimulatory effect. Consistently, hypoxia treatment increased sixfold HRELuc activity in 1833 cells that was counteracted by NS398 (Fig. 1c).

COX-2 and HIF-1 $\alpha$ expression in 1833-xenograft model of metastasis

We evaluated metastases 20 days after intracardiac-cell injection (Fig. 2). COX-2 localized in perinuclear/cytosolic and nuclear compartments of bone-metastatic cells. HIF-1 $\alpha$ localized prevalently in the cytosol, and also $20 \%$ of the nuclei of bone metastases were positive (60X magnification, inset). In addition, specific-HIF-1 $\alpha$ signal was detected in bone-marrow microenvironmental cells (20X magnification), possibly as consequence of metastasis engraftment. In fact, in control animals HIF-1 $\alpha$ specific signal was undetectable. HIF-1 $\alpha$ induction might depend on hypoxic conditions and/or growth-factor production [20,34].

Association of COX-2 and HIF-1 $\alpha$ in human specimens of bone metastasis

COX-2 and HIF-1 $\alpha$ association has never been investigated in human bone metastasis from breast carcinoma. Fig. 3a shows the immunohistochemistry of COX-2 and HIF-1 $\alpha$ in specimens from 2 patients, representative of 10 patients examined. Immunohistochemical images for patients 3 to 10 are given in Supplementary material. For all the patients examined, the percentage of cells positive for both COX-2 and HIF-1 $\alpha$ was more than $70 \%$. The presence of breast-carcinoma metastasis in the bones was evaluated by $\mathrm{H} \& \mathrm{E}$ staining, and by positive immunoreactivity for cytokeratines.

As shown in Fig. 3a and b, COX-2 accumulated predominantly in perinuclear and cytosolic compartments, but also a specific immunoreactivity in the nucleus was observed. HIF-1 $\alpha$ in patients $1,6,8$ and 9 completely localized in the nuclei; prevalent nucleic but also cytosolic HIF-1 $\alpha$ immunostaining was observed in the other patients (Fig. 3a and b; Supplementary material). Thus, $100 \%$ of the examined patients showed nuclear localization of HIF-1 $\alpha$ in bone metastases. The 
concomitant presence of COX-2 and HIF-1 $\alpha$ in nuclei might indicate their functional interaction, consistent with the in vitro experiments showing COX-2 and HIF-1 $\alpha$ co-localization as well as the regulation of HIF-1 $\alpha$ translocation and HIF-1 activity by COX-2.

1833 clone and MDA-MB231-parental cells differently responded to hypoxia and TGF- $\beta 1$

We investigated the molecular mechanism(s) involved in the control of COX-2 expression by hypoxia, the TGF- $\beta 1$ cross-talk, and the possible differences between 1833 and MDA-MB231 cells.

As shown in Fig. 4a, in stimulated 1833 cells COX-2-protein levels increased between 12 and $24 \mathrm{~h}$ : the effect of hypoxia (13-14-fold increase) was more than that of TGF- $\beta 1$ (about 5-6-fold increase). Differently, in MDA-MB231 cells TGF- $\beta 1$ progressively enhanced COX-2-protein levels, reaching the maximum at $12 \mathrm{~h}$ (6.5-fold increase), while hypoxia was ineffective. The gels for the two cell lines were run in parallel and developed concomitantly, showing that the COX-2protein level was 4-fold higher in MDA-MB231 than in 1833 cells.

The half-life of COX-2 was measured in the two cell lines under the studied stimuli, blocking protein synthesis with cycloheximide (Fig. 4b). Cycloheximide $(100 \mu \mathrm{g} / \mathrm{ml})$ was added to the cells exposed to 12-h hypoxia or TGF- $\beta 1$, and Western blots were performed using total-cell extracts (not containing nuclear proteins). Densitometric values were analysed by the least-squares method. In 1833 cells, hypoxia markedly reduced the half-life of COX-2: it was $24 \mathrm{~h}$ in control cells diminishing to $2 \mathrm{~h}$ under hypoxia. TGF- $\beta 1$ practically unaffected the control value. In MDAMB231 cells, TGF- $\beta 1$ reduced COX-2 half-life: it was $48 \mathrm{~h}$ in control cells and $13.5 \mathrm{~h}$ in TGF- $\beta 1$ treated cells.

To better clarify the strong decrease of COX-2 half-life in hypoxic-1833 cells, we performed immunofluorescence experiments (Fig. 4c). Hypoxia increased COX-2-fluorescence signal in nuclear and perinuclear compartments, but after 2-h cycloheximide treatment the enhanced 
fluorescence signal localized almost completely in the nuclei. A partial redistribution both in nucleus and cytosol occurred in 4-h cycloheximide treated cells. Thus, the rapid decline of COX-2 protein after cycloheximide, in the study of half-life, might largely depend on nuclear translocation of COX-2 in 1833 cells.

Further studies were performed with LLnL, a specific proteasome inhibitor (Fig. 4d). LLnL stabilized COX-2 between 6 and $24 \mathrm{~h}$ in hypoxic 1833 cells and in TGF- $\beta 1$-treated MDA-MB231 cells, possibly by preventing proteasomal degradation.

TGF- $\beta 1$ and HGF controlled the response to hypoxia in bone metastasis of breast cancer

We extended and deepened the studies on the role of growth factors in the hypoxic response by considering whether they were involved in $\mathrm{COX}-2$ transcription (Fig. 5). COX-2 transactivating activity was examined using two gene-reporters, that contained sequences spanning from -1432 to +59 and from -327 to +59 . The latter contains 4 Ets- 1 and 1 NF- $k$ B consensus sequences. COX-2(1432/+59)Luc shows upstream 1 consensus site for each of the following transcription factors: TCF, HIF-1, AP-1 and NF- $k$ B [13].

As shown in Fig. 5a, in 1833 and MDA-MB231 cells TGF- $\beta 1$ increased luciferase activity of both the constructs, while hypoxia was ineffective. The stimulatory effect of the combined stimuli seemed, therefore, to be due to TGF- $\beta 1$. Basal activities of COX-2-promoter constructs (1432/+59)Luc and (-327/+59)Luc were 2- and 1.5- fold higher in 1833 clone than in MDA-MB231 cells (data not shown).

HGF enhanced (about 2.5-fold) COX-2(-327/+59)Luc activity in 1833 but not in MDAMB231 cells (Fig. 5b). However, HGF increased COX-2 protein levels between 6 and $24 \mathrm{~h}$ in the two cell lines, but with different time-courses and extent. The differences in the COX-2-protein levels might depend on the higher basal level in MDA-MB231 than in 1833 cells, and on the 
involvement of transcription-independent mechanism(s), such as protein stabilization by HGF in MDA-MB231 cells (data not shown).

The release of TGF- $\beta 1$ and HGF augmented of about 5- and 2-fold in the conditioned medium of 1833 cells exposed to hypoxia, while only TGF- $\beta 1$ release doubled in hypoxic MDAMB231 cells (Fig. 5c).

Altogether, the data suggested that hypoxia did not act directly at transcriptional level, but COX-2 induction in 1833 cells was mediated by TGF- $\beta 1$ and HGF. Translational and posttranslational mechanisms seemed to participate in COX-2 protein accumulation in hypoxic-bone metastatic cells.

Then, we considered the transcription factors involved in COX-2 transactivation in response to the growth factors (Fig. 5d). First the cells, transfected with COX-2(-1432/+59)Luc, were exposed or not to TGF- $\beta 1$ in the presence of expression vectors for dominant negatives or specific inhibitors of the transcription factors showing consensus sequences in the promoter. In 1833 cells, $\triangle \mathrm{ARNT}, \Delta \mathrm{Ets} 1$ or CGP049090 reduced basal and TGF- $\beta 1$-stimulated luciferase activity, while TAM67 prevented of about $60 \%$ luciferase activity after TGF- $\beta 1$ exposure. In MDA-MB231 cells, SN50, TAM67 or CGP049090 reduced basal and TGF- $\beta 1$-stimulated luciferase activity, while $\Delta$ Ets1 prevented of about $95 \%$ luciferase activity after TGF- $\beta 1$ exposure. $\Delta$ ARNT was ineffective in MDA-MB231 cells. In further experiments, in 1833 cells we examined COX-2(-327/+59)Luc activity, that was responsive to HGF. $\triangle$ Ets1 reduced basal and HGF-stimulated luciferase activity, while SN50 showed an inhibitory effect only after HGF exposure.

Mechanisms of COX-2 induction by HGF

To further evaluate the mechanisms of COX-2 induction by HGF in 1833 cells, we examined whether the increase in COX-2 protein levels depended on stabilization beyond transcription. 1833 
cells were exposed to HGF also in the presence of LLnL. As shown in Fig. 6a, HGF increased COX-2-fluorescence signals in perinuclear and nuclear compartments. HIF-1 $\alpha$ showed a strong nuclear signal, and co-localized with COX-2 in this compartment. LLnL pre-treatment principally enhanced COX-2, showing strong fluorescence signals at perinuclear and nuclear levels. Western blot analysis was consistent with the stabilization of COX-2 protein, enhanced by HGF, after proteasome blockade (Fig. 6b). The half-life of COX-2 was unchanged by HGF treatment (Fig. 6c). In HGF-treated 1833 cells (Fig. 6d), the activities of gene reporters driven by NF- $k \mathrm{~B}$ and Ets1 multimers increased 2.2-fold and 4.2-fold, respectively, confirming their role in COX-2 transcription.

Effect of TGF- $\beta 1$ and hypoxia on transcription-factor activities

Based on the data obtained with dominant negatives and specific inhibitors, we examined the transcription factors in response to TGF- $\beta 1$ or hypoxia. HIF-1 is an $\alpha / \beta$ heterodimer [14], and the regulation of the expression of these subunits might depend on the stimuli and the cell type. Under hypoxia, HIF-1 $\alpha$-protein level while augmenting (5-fold) in 1833 and MDA-231BO cells, only doubled in MDA-MB231 cells (Fig. 7a). The HIF-1ß/ARNT-wild type form (97 kDa) was predominant in nuclei of the two bone-metastatic clones, increasing after hypoxia. In invasive MDA-MB231 cells HIF-1ß/ARNT protein level, low in control nuclei, was reduced (-85\%) by hypoxia (Fig. 7a). Low-molecular-weight (36 kDa) variant of HIF-1ß/ARNT was expressed in parental MDA-MB231 cells and in the subclones (data not shown).

In 1833 cells, hypoxia stimulated HIF-1 activity (6-fold increase in HRELuc) (Fig. 7b), while decreasing TCF activity (-40\% TOPFLASHLuc) (Fig 7c). In TGF- $\beta 1$-treated 1833 cells, NF$k \mathrm{~B}$, AP-1 and Ets-1 activities increased (2-3-fold) (Fig 7c). In MDA-MB231 cells, HIF-1 $\beta$ expression vector transfection rescued HRELuc activity under hypoxia (Fig 7b), and TGF- $\beta 1$ tripled NFkBLuc and doubled TOPFLASHLuc (Fig 7c). 
HRELuc was activated in hypoxic MDA-231BO cells, being practically unmodified by HIF$1 \beta$-expression vector transfection (Fig. 7d).

HIF-1 $\alpha$ controlled transcription factor activities

TGF- $\beta 1$ and HGF enhanced HIF-1 $\alpha$ protein level in 1833 cells, while decreasing that of MDAMB231 cells (Fig. 8a and b). We reproduced endogenous-HIF-1 $\alpha$ overexpression by transfecting HIF-1 $\alpha$-expression vector, and we studied the activities of the gene reporters driven by multimers of the consensus sequences. The transcription factors examined were activated by HIF-1 $\alpha$ overexpression, except TCF. In fact, TOPFLASHLuc was reduced of about $60 \%$ (Fig. 8c). It is worth noting that the activity of the HRE multimer, very elevated under basal conditions, doubled in 1833 cells transfected with HIF-1 $\alpha$. This overexpression of the exogenous $\alpha$ subunit seemed to partly reproduce the effect of TGF- $\beta 1$ in the regulation of COX- 2 transcription, because HIF-1 activation is complex requiring translocation and phosphorylation of the $\alpha$ subunit, beyond stabilization, and the possible co-operation with other transcription factors and transcriptional coactivators [35].

Target genes controlled by COX-2-signaling pathway, and possible interaction with HGF/Met system

The gene expression pattern of 1833 cells, under TGF- $\beta 1$ or hypoxia exposure, was examined after treatment with NS398 or SB431542 to evaluate the involvement of COX-2 signaling and TGF- $\beta 1$ typeI receptor, respectively. In Fig. 9a, the results of experiments performed with total protein extracts are reported. TGF- $\beta 1$ and hypoxia increased HGF protein levels. The HGF-protein expression was enhanced by NS398 or SB431542 in the presence of TGF- $\beta 1$. In contrast, TGF- $\beta 1$ - 
typeI receptor blockades reduced HGF-protein level under hypoxia. Met 170 and $145 \mathrm{kDa}$ were the precursor and the membrane-spanning subunit, respectively. Hypoxia-stimulatory effects on Met and VEGF were partly prevented by COX-2 and TGF- $\beta 1$-typeI receptor blockades, respectively.

For nuclear extracts (Fig. 9b), differences were observed between control (10\% FBS) and starved cells depending on the gene. CXCR4-protein level was reduced (from 50 to $80 \%$ ) by hypoxia, with reversion after TGF- $\beta 1$-typeI receptor blockade, and was unchanged by TGF- $\beta 1$ treatment, in the presence or the absence of the inhibitors. Noteworthy, CXCR4-protein level was very faint using total extracts (data not shown). Nuclear COX-2 was induced by hypoxia, and COX2 and TGF- $\beta 1$-typeI receptor blockades oppositely affected COX-2 levels. In particular, NS398 enhanced nuclear COX-2 protein level between 6 and 18 h of hypoxia, while decreasing hypoxic effect $(-45 \%)$ at $24 \mathrm{~h}$. The latter data was in agreement with immunofluorescence experiments (Fig. 1a). HIF-1 $\alpha$ induction by both stimuli was prevented by the inhibitors used.

Summary of molecular events involved in COX-2/HIF-1 $\alpha$ interaction in bone metastasis

In Fig. 10 we show TGF- $\beta 1$ and HGF autoregulatory loops, triggered in response to hypoxia, that were responsible for COX-2 expression and HIF-1 activity, controlling a panel of genes relevant for the bone-metastatic process.

\section{Discussion}

Physical (hypoxia) and biological (growth factors) stimuli of bone-metastasis microenvironment seemed to favour COX-2-HIF-1 functional interaction, thus affecting gene expression in breast carcinoma metastatic cells and human metastasis with bone avidity. This was suggested by data 
obtained with COX-2 inhibitor, blocking HIF-1 transactivating activity, and by the observed nuclear COX-2-HIF-1 $\alpha$ co-localization, using different in vitro and in vivo models and human specimens.

First, our study extended the knowledge of the molecular events involved in bone metastatisation, and demonstrated that 1833-bone metastatic clone differed from highly-invasive parental MDA-MB231 cells not only for gene-expression level [6], but especially for the remarkable plasticity and adaptability of the gene profile to multiple-concomitant microenvironmental stimuli. This depended principally on functionality of HIF-1-transcription factor in 1833 cells, in agreement with our previous work [3], a molecular characteristic shared with MDA-231BO cells also endowed of bone tropism.

Metastatic cells might produce HGF and TGF- $\beta 1$ in bone-hypoxic environment, and HGF might substitute for TGF- $\beta 1$ during metastasis progression. In fact, TGF- $\beta 1$ seemed to exert a negative effect on HGF signaling, because TGF- $\beta 1$-typeI receptor blockade enhanced HGF-protein level in 1833 cells. Thus, the metastasis-gene signature was likely to be strongly controlled at the secondary-bone site, undergoing changes in stimuli composition after metastatic-cell engraftment [2]. The composition of bone microenvironment may vary depending on the growth phase from early metastasis, leaving dormancy, until acquisition of a more aggressive phenotype during metastasis progression. Consistently, elevated HIF-1 $\alpha$ expression was observed in cells of metastasis microenvironment of the xenograft model, also supporting the statement: metastatic cells in the bone exploit surrounding cells to their own ends, resulting in invasion, neoangiogenesis and ultimately in inappropriate growth and metastasis establishment [5]. Therefore, in our model HIF$1 \alpha$ expression was not limited to 1833 metastasis, but participated to supportive-cell function, compatible with a "pre-metastatic niche". Altogether, these properties probably render so difficult to therapeutically intervene halting bone metastases.

Second, we identified the molecular mechanisms of hypoxia as leading stimulus in bone metastasis. Through HGF and TGF- $\beta 1$ release, possibly activating autoregulatory loops with Met and TGF- $\beta 1$ receptors, hypoxia affected COX-2 and the gene-pattern downstream including HIF- 
1a. COX-2 and HIF-1 $\alpha$ genes were co-expressed in nuclei of human-bone metastasis specimens, index of reciprocal influence. Studies in vitro showed, in fact, that COX-2 participated in HIF-1 $\alpha$ nuclear translocation in hypoxic-1833 cells, and the shuttling of endogenously overexpressed HIF$1 \alpha$ was critical for HIF-1 activity. COX-2 blockade prevented both these molecular events.

The precise molecular roles played by COX-2 and HIF-1 in the metastatic process are here clarified. COX-2 expression and localization were deeply studied in a wide number of specimens of human breast-carcinoma bone metastasis. Previously, Hiraga et al. [16] evaluated COX-2 by immunohistochemistry in 1 bone metastasis from breast cancer, suggesting an involvement of COX-2 in osteolysis using an animal model. Because the cytoplasm is the site of new-protein synthesis, COX-2 accumulation in the nucleus of human-bone metastasis was indicative of active COX-2-nuclear import in transcriptionally activated cells. Perichromatin regions of the nucleus are sites of active transcription [36]. HIF-1 functioned in hypoxic 1833 and MDA-231BO but not in MDA-MB231 cells. The MDA-MB231 cells have a mutated HIF-1ß/ARNT subunit [37], and a reduced level of the wild-type form was observed by us under hypoxia. The data were consistent with an alternative-RNA splicing in hypoxic conditions reducing the level of HIF-1 $\beta$ /ARNT wildtype protein [38].

A strong HIF-1 $\alpha$-nuclear signal was observed in all the human-metastasis specimens. HIF$1 \alpha$ and COX-2 co-localization in nuclei of human-bone metastasis not only validated in vivo the functional interaction demonstrated in vitro, but might have also a diagnostic significance for metastasis relapse after therapy, and prognostic significance to individuate primary tumor. HIF-1 $\alpha$ localizes in nuclei of bone metastasis of prostate carcinoma [26], but a concomitant COX-2-nuclear expression and functional interaction are not shown.

In primary lobular and ductal mammary tumors, $\mathrm{COX}-2$ is present in plasma-membrane caveolae and cytosol, respectively [39], without the nuclear and perinuclear localization observed by us in bone metastasis. 
The regulation of COX-2 in 1833 cells was complex. Hypoxia regulated indirectly COX-2 transactivation via HGF and TGF- $\beta 1$, controlling the activity of specific transcription factors that bind to COX-2 promoter, i.e. AP-1 and NF- $k$ B, while HIF-1, Ets1 and $\beta$-catenin/TCF controlled both basal and activated COX-2 transactivation. HIF- $1 \alpha$ protein, stabilized by HGF and TGF- $\beta 1$, regulated the network of transcription factors including HIF-1. Thus, HIF-1 activity was important for COX-2 transactivation because the blockade of HIF-1 $/$ ARNT with the dominant negative largely prevented luciferase activity. As other early genes, COX-2 is regulated not only at transcriptional level but also at translational and post-translational levels [40]. A rapid downregulation of cellular COX-2 occurring under hypoxia in 1833 cells, depended on nuclear translocation and proteasomal degradation, mechanisms important to control COX-2-signaling function on gene expression.

Altogether, the relevance of our work was that COX-2 signaling regulated HIF-1 activity by controlling HIF-1 $\alpha$ expression and nuclear translocation. Active-transcription factors are localized in nuclear matrix, where signal-transduction mechanism(s) are working [36]. The blockade of enhanced TGF- $\beta 1$-typeI receptor prevented COX-2 and HIF-1 $\alpha$ expression in nuclei, consistent with an enhancement of TGF- $\beta 1 /$ TGF- $\beta 1$-typeI receptor couple, condition necessary for the autoregulatory-loop triggering [41].

Based on this complex orchestration of signaling pathways, 1833-bone metastasis possibly differed from MDA-MB231-bone metastasis, in which TGF- $\beta 1$ seems the only stimulus responsible for COX-2 expression and function [16]. In cells practically unresponsive to hypoxia such as MDAMB231, being HIF-1 unaffected, TGF- $\beta 1$ principally induced NF- $k$ B. The ligand TGF- $\beta 1$ signals from the receptor to the nucleus using a set of proteins termed Smads, and NF- $k$ B might exert inhibitory roles blocking Smad phosphorylation [42]. Consistently, we observed that HIF-1 $\alpha$, a target gene of NF- $k$ B [15], was down-regulated in TGF- $\beta 1$-exposed MDA-MB231 cells. Our present data possibly explain why knockdown of HIF-1 $\alpha$ has not additive effects with TGF- $\beta$ 
blockade against MDA-MB231-bone metastasis [31]. In the case of 2-metoxyestradiol (2ME2), showing a relatively small-inhibitory effect on hypoxia-induced HIF-1-transcriptional activity [43], it affects bone-metastasis burden possibly as anticancer agent with antiproliferative, antiangiogenic and proapoptotic roles by disrupting the microtubule skeleton. Only after exogenous Smads overexpression, VEGF transactivation increases in response to TGF- $\beta$ [31].

Third, due to the relationship with HIF-1 $\alpha /$ HIF-1 activity and considering the HIF-1-target genes, completely new functions beyond osteolysis can be proposed for COX-2 in human-bone metastasis, such as angiogenesis (VEGF), homing (CXCR4) and protection from apoptosis. HIF-1 $\alpha$ is an anti-apoptotic gene [14, 44, 45], while COX-2 is pro-apoptotic [46]. Opposite regulation of HIF-1 $\alpha$ - and COX-2-protein levels was observed in nuclei of hypoxic-1833 cells under COX-2signaling blockade, as a possible consequence of a feed-back control mechanism that enhanced COX-2-protein level in the absence of HIF-1 $\alpha$ protein.

Hypoxia decreased nuclear CXCR4-protein level in 1833 cells through TGF- $\beta 1$-typeI receptor and COX-2. CXCR4 down-regulation might be important for the homing of metastatic cells, preventing their recirculation, while CXCL12 drives them to bone-secondary site. CXCR4 in breast cancer tissues shows a variable subcellular localization, e.g. on the plasma membrane, in the cytoplasm, or even in the nucleus [47]. CXCR4-nuclear localization occurs also in hemangioblastoma and clear cell-renal carcinoma [48]. Various receptors are known to function intranuclearly, possibly affecting specific signaling pathways [27].

The VEGF expression in metastatic cells, under the influence of microenvironment stimuli that activated HIF-1, might be important for neoangiogenesis at the secondary-growth site. The blockade of TGF- $\beta 1$-typeI receptor reduced VEGF expression in 1833 cells.

Surprisingly, in TGF- $\beta 1$-treated 1833 cells a negative interrelation occurred between TGF$\beta 1$ and HGF expression, as previously reported for fibroblast-HGF and tumor cell-TGF- $\beta 1$ [49], and COX-2 influenced HGF-protein level. Vice versa, HGF regulated COX-2 via Ets-1 and NF- $k$ B. 
The key role exerted by microenviromental stimuli on metastatic phenotype may be of great importance from a therapeutic point of view, because it would be more useful and easier to affect gene profile at epigenetic level than to modify the genotype. Even if hypoxia-response gene signature is not able to stratify patients for risk of bone metastasis, based on gene expression profile of primary-breast tumor, the strategy of targeting HIF-1 $\alpha$ for treatment of bone metastasis remains valid [30]. We demonstrated that hypoxia led to an adaptive response via COX-2, orchestrated by HIF-1, that might be crucial for metastasis progression and therapy resistance, responsible for poor patient outcome. Downstream targets of HIF-1 $\alpha /$ HIF-1 would be considered as hypoxia biomarkers, and the identification of the molecular biomarkers COX-2 and HIF-1 $\alpha$, with a potential to predict metastasis-treatment outcome, is essential for selecting patients to receive the most beneficial therapy.

\section{Acknowledgments}

This study was supported by founds from Ministero Istruzione-Università-Ricerca, PRIN-2007-1225201001-14; Ministero Salute, Ricerca Corrente-4029.

\section{References}

1. Psaila B, Lyden D (2009) The metastatic niche: adapting the foreign soil. Nat Rev Cancer 9:285-293

2. Previdi S, Maroni P, Matteucci E, Broggini M, Bendinelli P, Desiderio MA (2010) Interaction between human-breast cancer metastasis and bone microenvironment through activated hepatocyte growth factor/Met and $\beta$-catenin/Wnt pathways. Eur J Cancer 46:16791691

3. Bendinelli P, Matteucci E, Maroni P, Desiderio MA (2009) NF-kB activation, dependent on acetylation/deacetylation, contributes to HIF-1 activity and migration of bone metastatic breast carcinoma cells. Mol Cancer Res 7:1328-1341 
4. Chiodoni C, Colombo MP, Sangaletti S (2010) Matricellular proteins: from homeostasis to inflammation, cancer and metastasis. Cancer Metastasis Rev 29: 295-307

5. Joyce JA, Pollard JW (2009) Microenvironmental regulation of metastasis. Nat Rev Cancer 9:239-252

6. Kang Y, Siegel PM, Shu W, Drobnjak M, Kakonen SM, Cordón-Cardo C et al (2003) A multigenic program mediating breast cancer metastasis to bone. Cancer Cell 3:537-549

7. Weigelt B, Peterse JL, van't Veer LJ (2005) Breast cancer metastasis: markers and models. Nat Rev Cancer 5:591-602

8. Klein A, Olendrowitz C, Schmutzler R, Hampl J, Schlag PM, Mass N et al (2009) Identification of brain- and bone-specific breast cancer metastasis genes. Cancer Lett 276:212-220

9. Kopfstein L, Christofori G (2006) Metastasis: cell-autonomous mechanisms versus contributions by the tumor microenvironment. CMLS-Cell Mol Life Sci 63:449-468

10. Ridolfi E, Matteucci E, Maroni P, Desiderio MA (2008) Inhibitory effect of HGF on invasiveness of aggressive MDA-MB231 breast carcinoma cells, and role of HDACs. Br J Cancer 99:1623-1634

11. Kingsley LA, Fournier PG, Chirgwin JM, Guise TA (2007) Molecular biology of bone metastasis. Mol Cancer Ther 6:2609-2617

12. Fry CJ, Farnham PJ (1999) Context-dependent transcriptional regulation. J Biol Chem 274:29583-29586

13. Lee YH, Suzuki YJ, Griffin AJ, Day RM (2008) Hepatocyte growth factor regulates cyclooxygenase- 2 expression via $\beta$-catenin, Akt, and p42/p44 MAPK in human bronchial epithelial cells. Am J Physiol Lung Cell Mol Physiol 294:L778-L786

14. Semenza GL (2001) HIF-1 and mechanisms of hypoxia sensing. Curr Opin Cell Biol $13: 167-171$ 
15. Tacchini L, Dansi P, Matteucci E, Desiderio MA (2001) Hepatocyte growth factor signalling stimulates hypoxia inducible factor-1 (HIF-1) activity in HepG2 hepatoma cells. Carcinogenesis 22:1363-1371

16. Hiraga T, Myoui A, Choi ME, Yoshikawa H, Yoneda T (2006) Stimulation of cyclooxygenase- 2 expression by bone-derived transforming growth factor-beta enhances bone metastases in breast cancer. Cancer Res 66:2067-2073

17. Singh B, Berry JA, Shoher A, Ayers GD, Wei C, Lucci A (2007) COX-2 involvement in breast cancer metastasis to bone. Oncogene 26:3789-3796

18. Li Z, Schem C, Shi YH, Medina D, Zhang M (2008) Increased COX2 expression enhances tumor-induced osteoclastic lesions in breast cancer bone metastasis. Clin Exp Metastasis 25:389-400

19. Pennacchietti S, Michieli P, Galluzzo M, Mazzone M., Giordano S, Comoglio PM (2003) Hypoxia promotes invasive growth by transcriptional activation of the met protooncogene. Cancer Cell 3:347-361

20. Desiderio MA (2007) Hepatocyte growth factor in invasive growth of carcinomas. CMLSCell Mol Life Sci 64:1341-1354

21. Balkwill F (2004) Cancer and the chemokine network. Nat Rev Cancer 4:540-550

22. Shim H, Lau SK, Devi S, Yoon Y, Cho HT, Liang Z (2006) Lower expression of CXCR4 in lymph node metastases than in primary breast cancers: potential regulation by liganddependent degradation and HIF-1 $\alpha$. Biochem Biophys Res Commun 346:252-258

23. Yoshitake N, Fukui H, Yamagishi H, Sekikawa A, Fujii S, Tomita S et al (2008) Expression of SDF-1 $\alpha$ and nuclear CXCR4 predicts lymph node metastasis in colorectal cancer. Br J Cancer 98:1682-1689

24. Semenza GL (2002) HIF-1 and tumor progression: pathophysiology and therapeutics. Trends Mol Med 8:S62-S67 
25. Chen HH, Su WC, Lin PW, Guo HR, Lee WY (2007) Hypoxia-inducible factor-1alpha correlates with MET and metastasis in node-negative breast cancer. Breast Cancer Res Treat 103:167-175

26. Zhong H, De Marzo AM, Laughner E, Lim M, Hilton DA, Zagzag D et al (1999) Overexpression of hypoxia-inducible factor $1 \alpha$ in common human cancers and their metastases. Cancer Res 59:5830-5835

27. Matteucci E, Bendinelli P, Desiderio MA (2009) Nuclear localization of active HGF receptor Met in aggressive MDA-MB231 breast carcinoma cells. Carcinogenesis 30:937945

28. Lepourcelet M, Chen Y-N, France DS, Wang H, Crews P, Petersen F et al (2004) Smallmolecule antagonists of the oncogenic Tcf/ $\beta$-catenin protein complex. Cancer Cell 5:91-102

29. Yue L, Christman JW, Mazzone $T$ (2008) Tumor necrosis factor-alpha-mediated suppression of adipocyte apolipoprotein E gene transcription: primary role for the nuclear factor (NF)-kappaB pathway and NFkappaB p50. Endocrinology 149: 4051-4058

30. Lu X, Yan CH, Yuan M, Wei Y, Hu G, Kang Y (2010) In vivo dynamics and distinct functions of hypoxia in primary tumor growth and organotropic metastasis of breast cancer. Cancer Res 70:3905-3914

31. Dunn LK, Mohammad KS, Fournier PG, McKenna CR, Davis HW, Niewolna M et al (2009) Hypoxia and TGF- $\beta$ drive breast cancer bone metastases through parallel signaling pathways in tumor cells and the bone microenvironment. Plos ONE 4:1-20

32. Moore AE, Greenhough A, Roberts HR, Hicks DJ, Patsos HA, Williams AC et al (2009) HGF/Met signalling promotes $\mathrm{PGE}_{2}$ biogenesis via regulation of COX-2 and 15-PGDH expression in colorectal cancer cells. Carcinogenesis 30:1796-1804 
33. Liu XH, Kirschenbaum A, Lu M, Yao S, Dosoretz A, Holland JF et al (2002) Prostaglandin $\mathrm{E}_{2}$ induces hypoxia-inducible factor- $1 \alpha$ stabilization and nuclear localization in human prostate cancer cell line. J Biol Chem 277:50081-50086

34. Eliasson P, Jönsson J-I (2009) The hematopoietic stem cell niche: low in oxygen but a nice place to be. J Cell Physiol 222:17-22

35. Lisy K, Peet DJ (2008) Turn me on: regulating HIF transcriptional activity. Cell Death Differ 15:642-649

36. Parfenova H, Parfenov VN, Shlopov BV, Levine V, Falkos S, Pourcyrous M et al (2001) Dynamics of nuclear localization sites for COX-2 in vascular endothelial cells. Am J Physiol Cell Physiol 281:C166-C178

37. Wilson CL, Thomsen J, Hoivik DJ, Wormke MT, Stanker L, Holtzapple C et al (1997) Aryl hydrocarbon $(\mathrm{Ah})$ nonresponsiveness in estrogen receptor-negative MDA-MB231 cells is associated with expression of variant Arnt protein. Arch Biochem Biophys 346:65-73

38. Hirschfeld M, zur Hausen A, Bettendorf H, Jäger M, Stickeler E (2009) Alternative splicing of Cyr61 is regulated by hypoxia and significantly changed in breast cancer. Cancer Res 69:2082-2090

39. Perrone G, Zagami M, Altomare V, Battista C, Morini S, Rabitti C (2007) COX-2 localization within plasma membrane caveolae-like structures in human lobular intraepithelial neoplasia of the breast. Virchows Arch 451:1039-1045

40. Singh-Ranger G, Salhab M, Mokbel K (2008) The role of cyclooxygenase-2 in breast cancer: review. Breast Cancer Res Treat 109:189-198

41. Li J-J, Lu J, Kaur C, Sivakumar V, Wu C-Y, Ling E-A (2008) Effects of hypoxia on expression of transforming growth factor- $\beta 1$ and its receptors I and II in the amoeboid microglial cells and BV-2 cells. Neuroscience 156:662-672 
42. Roman-Blas JA, Stokes DG, Jimenez SA (2007) Modulation of TGF- $\beta$ signaling by proinflammatory cytokines in articular chondrocytes. Osteoarthritis Cartilage 15:1367-1377

43. Chua YS, Chua YL Hagen T (2010) Structure activity analysis of 2-methoxyestradiol analogues reveals targeting of microtubules as the major mechanism of antiproliferative and proapoptotic activity. Mol Cancer Ther 9:224-235

44. Rankin EB, Giaccia AJ (2008) The role of hypoxia-inducible factors in tumorigenesis. Cell Death and Diff 15:678-685

45. Marignol L, Coffey M, Lawler M, Hollywood D (2008) Hypoxia in prostate cancer: a powerful shield against tumour destruction? Cancer Treat Rev 34:313-327

46. Lin H-Y, Davis PJ, Tang H-Y, Mousa SA, Luidens MK, Hecherbergs AH et al (2009) The pro-apoptotic action of stilbene-induced COX-2 in cancer cell: convergence with the antiapoptotic effect of thyroid homone. Cell Cycle 8:1877-1882

47. Schmid BC, Rudas M, Rezniczek GA, Leodolter S, Zeillinger R (2004) CXCR4 is expressed in ductal carcinoma in situ of the breast and in atypical ductal hyperplasia. Breast Cancer Res Treat 84:247-250

48. Zagzag D, Krishnamachary B, Yee H, Okuyama H, Chiriboga L, Ali MA et al (2005) Stromal cell-derived factor-1 $\alpha$ and CXCR4 expression in hemangioblastoma and clear cellrenal cell carcinoma: von Hippel-Lindau loss-of-function induces expression of a ligand and its receptor. Cancer Res 65:6178-6188

49. Matsumoto K, Nakamura T (2006) Hepatocyte growth factor and the Met system as a mediator of tumor-stromal interactions. Int J Cancer 119:477-483 


\section{Legends to Figures}

Fig. 1 Intracellular localization of HIF-1 $\alpha$ depended on COX-2. The effect of hypoxia and the concomitant exposure to NS398 (COX-2 inhibitor) were analyzed by a immunofluorescence and $\mathbf{b}$ Western blot analyses. In Panel a, representative immunofluorescence images of experiments performed in triplicate. Merge I, COX-2/DAPI, merge II, HIF-1 $\alpha / \mathrm{DAPI}$; merge III, COX-2/HIF-1 $\alpha$. For $\mathbf{b}$, the numbers at the bottom of the Western blots indicate the fold-variations vs. control cells taken as 1. B23 was used for normalization. All the experiments were repeated three times with similar results. c Transient transfection of HRE-multimer gene reporter. The histograms indicate the absolute values for Firefly/Renilla luciferase-activity ratios. Hyp: hypoxia. The data are the means \pm S.E. of three independent experiments performed in triplicate. $* * P<0.005$ vs. control; ${ }^{\Delta} P<0.05$ vs. hypoxia-treated cells.

Fig. 2 Immunohistochemistry analysis of COX-2 and HIF-1 $\alpha$ in control and bone-metastasis bearing animals. COX-2 immunostaining of two serial sections (60X magnification). Insets: black arrows, perinuclear distribution; white arrows, nuclear localization. HIF-1 $\alpha$ immunostaining of serial sections (20X and 60X magnifications). Inset: nuclear and cytosolic distribution. The images are representative of experiments performed in triplicate. GP, growth plate; BM, bone marrow; M, metastasis; Bo, bone.

Fig. 3 COX-2 and HIF-1 $\alpha$ in human specimens of bone metastasis from breast cancer. a Representative immunohistochemistry images from two patients. Insets: black arrow, perinuclear distribution; white arrows, nuclear localization. pCK, pancytokeratins. b Intracellular localization and expression of COX-2 and HIF-1 $\alpha$ in 10 patients with bone metastasis. +, Mild expression; ++, moderate expression; +++, abundant expression. 
Fig. 4 Regulation of COX-2-protein levels by microenvironmental stimuli. a Time-courses of COX-2 in response to TGF- $\beta 1$ and/or hypoxia. The numbers at the bottom indicate the foldvariations vs. starved (st) cells taken as 1 . Vinculin was used for normalization. The experiments were repeated three times with similar results. b COX-2 half-life after the two stimuli. The graphs are representative of experiments repeated three times.

$\bullet$, control;

$\boldsymbol{\Delta}$, hypoxia;

घ, TGF- $\beta 1$. $\mathbf{c}$ Representative immunofluorescence images of experiments performed in triplicate. CHX, cycloheximide. d Western blot analysis of total extracts. The numbers at the bottom indicate the fold-variations vs. untreated cells taken as 1 . Vinculin was used for normalization. The experiments were repeated three times with similar results.

Fig. 5 COX-2 transactivation after TGF- $\beta 1$, HGF and hypoxia. In a and $\mathbf{b}$, the cells were transiently transfected with COX-2-promoter constructs, and the histograms indicate the foldvariations of Firefly/Renilla luciferase activity ratio vs. untreated cells taken as 1. Hyp: hypoxia. The data are the means \pm S.E. of three independent experiments performed in triplicate. ${ }^{*} P<0.05$ vs. untreated cells; ${ }^{\Delta} P<0.05$ vs. hypoxia-treated cells. In $\mathbf{b}$, Western blots performed with total extracts from cells exposed to HGF. The numbers at the bottom indicate the fold-variations vs. respective starved (st) cells taken as 1 . Vinculin was used for normalization. The experiments have been repeated three times with similar results. $\mathbf{c}$ Immunoassays of TGF- $\beta 1$ and HGF in conditioned medium. d Transient transfection of COX-2-promoter constructs, and treatment with dominant negatives or inhibitors. The histograms indicate the fold-variations of Firefly/Renilla luciferase activity ratio vs. untreated cells taken as 1 . The data are the means \pm S.E. of three independent experiments performed in triplicate. ${ }^{*} P<0.05$ and $* * P<0.005$ vs. starved (st) cells; ${ }^{\Delta} P<0.05$, ${ }^{\Delta \Delta} P<0.005,{ }^{\Delta \Delta \Delta} P<0.001$ vs. TGF- $\beta 1-$ or HGF-treated cells. 
Fig. 6 Control of COX-2 protein expression by HGF. 1833 cells were exposed to HGF in the presence or the absence of LLnL. a Representative immunofluorescence images of experiments performed in triplicate. Merge I, COX-2/DAPI, merge II, HIF-1 $\alpha /$ DAPI; merge III, COX-2/HIF-1 $\alpha$. b Western blot performed with total extracts. The numbers at the bottom indicate the fold-variations vs. starved (st) cells taken as 1 . Vinculin was used for normalization. The experiments have been repeated three times with similar results. c COX-2 half-life after HGF exposure. The graph is representative of experiments repeated three times. $\diamond$, control; $\mathbf{\square}$, HGF. d The cells were transiently transfected with gene reporters, and the histograms indicate the fold-variations of Firefly/Renilla luciferase activity ratio vs. untreated cells taken as 1 . The data are the means \pm S.E. of three independent experiments performed in triplicate. $* P<0.05$ and $* * P<0.005$ vs. untreated cells.

Fig. 7 Transcription-factor transactivation. a Endogenous HIF-1 $\alpha$ and HIF-1 $\beta$ in cells exposed to 24-h hypoxia. The numbers at the bottom of the Western blots indicate the fold-variations vs. control-1833 cells taken as 1 . B23 was used for normalization. The images are representative of three independent experiments. b and c The cells were transiently transfected with the gene reporters and were exposed to TGF- $\beta 1$ or hypoxia (Hyp), in the presence or the absence of HIF-1 $\beta$ expression vector. The histograms indicate the fold-variations of Firefly/Renilla luciferase activity ratio vs. untreated cells taken as 1 . The data are the means \pm S.E. of three independent experiments performed in triplicate. ${ }^{*} P<0.05, * * P<0.005$ and $* * * P<0.001$. vs. untreated cells; ${ }^{\Delta \Delta} P<0.005$ vs. TGF- $\beta 1$-treated cells. The absolute basal values for Firefly/Renilla activity ratios were the following. In 1833 cells: $23.31 \pm 4.24$ (HRE), 7.95 \pm 0.91 (NF- $k \mathrm{~B}$ ), $20.74 \pm 2.98$ (AP-1), 8.03 \pm 0.86

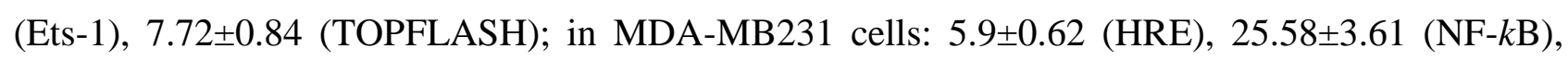
63.72 \pm 7.38 (AP-1), 4.82 \pm 0.52 (Ets-1), 18.03 \pm 2.07 (TOPFLASH). d Activity of HRE-multimer gene reporter in hypoxic MDA-231BO cells. The effect of HIF-1 $\beta$-expression vector was studied. 
The histograms indicate the fold-variations of Firefly/Renilla luciferase activity ratio vs. untreated cells taken as 1 . The data are the means \pm S.E. of three independent experiments performed in triplicate. ${ }^{*} P<0.05$ vs. untreated cells. The absolute basal value for Firefly/Renilla activity ratio of HRELuc in MDA-231BO was 12.03 \pm 1.90 .

Fig. 8 Cellular HIF-1 $\alpha$-expression under microenvironmental stimuli, and role in the control of transcription factors. In $\mathbf{a}$ and $\mathbf{b}$ nuclear extracts, prepared from cells exposed to TGF- $\beta 1$ or HGF, were analyzed by Western blot. The numbers at the bottom indicate the fold-variations vs. respective starved (st) cells taken as 1. B23 was used for normalization. The images are representative of three independent experiments. c Co-transfection of gene reporters and HIF-1 $\alpha$ expression vector. The histograms indicate the absolute values for Firefly/Renilla luciferase activity ratio. The data are the means \pm S.E. of three independent experiments performed in triplicate. ${ }^{*} P<$ 0.05 and $* * P<0.005$ vs. HIF-1 $\alpha$-untransfected cells.

Fig. 9 Genes regulated by COX-2 and TGF- $\beta 1$-typeI receptor. The numbers at the bottom of the Western blots indicate the fold-variations vs. untreated cells taken as 1. For Met, the numbers regard the $145 \mathrm{kDa}$ band. Vinculin and B23 were used for normalization. The experiments have been repeated three times with similar results. NS: NS398, COX-2 inhibitor; SB: SB431542, TGF$\beta 1$-typeI receptor inhibitor.

Fig. 10 Scheme representing the role of TGF- $\beta 1$ and HGF released by 1833 cells under hypoxia on COX-2 induction, HIF-1 activity and gene expression downstream. 
a

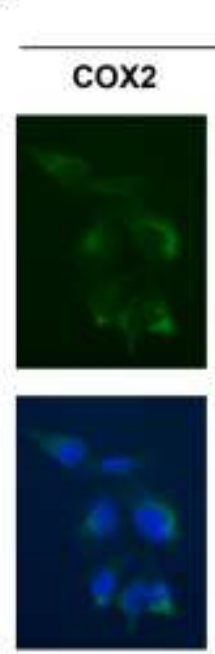

merge I
C
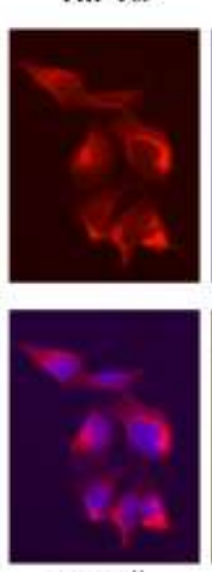

merge II
DAPI
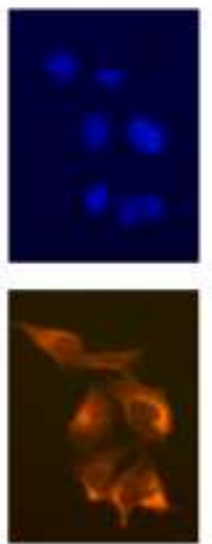

merge III
1833

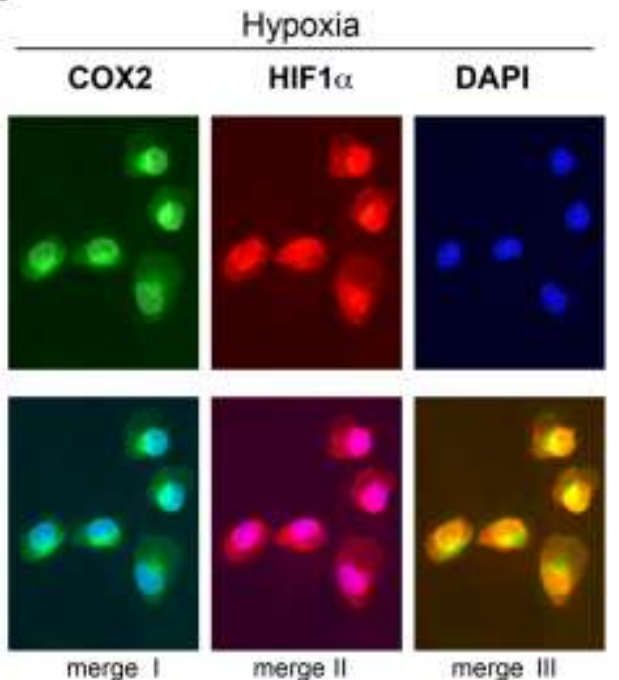

Hypoxia+NS398

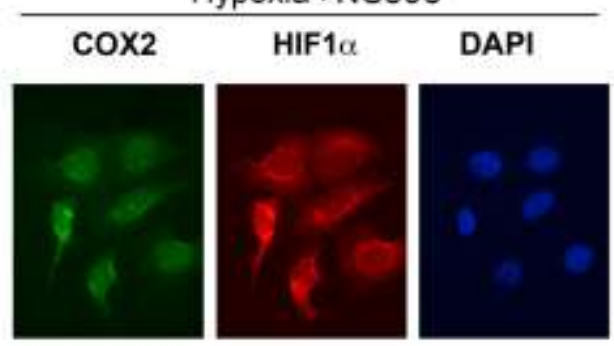

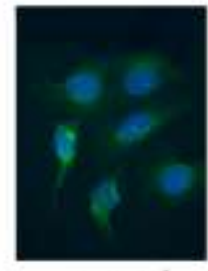

merno 1

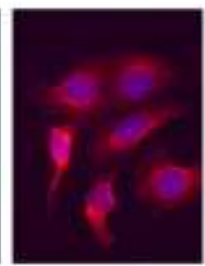

merge II

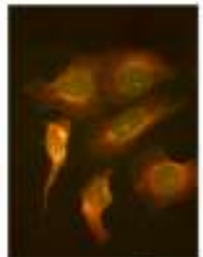

merge III

b

$$
\text { c }
$$

1833

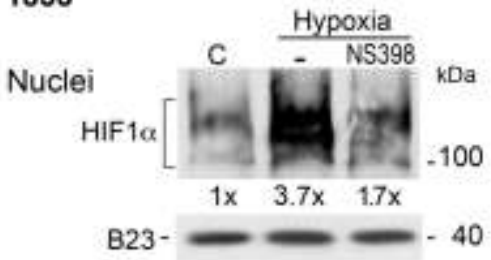

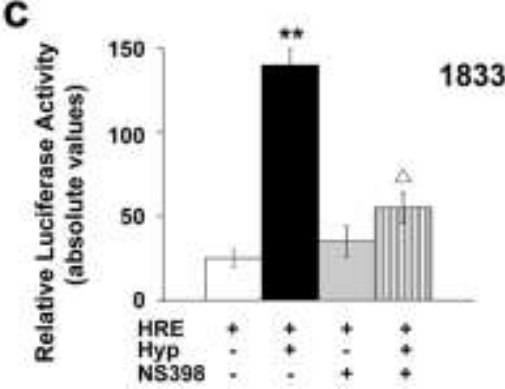



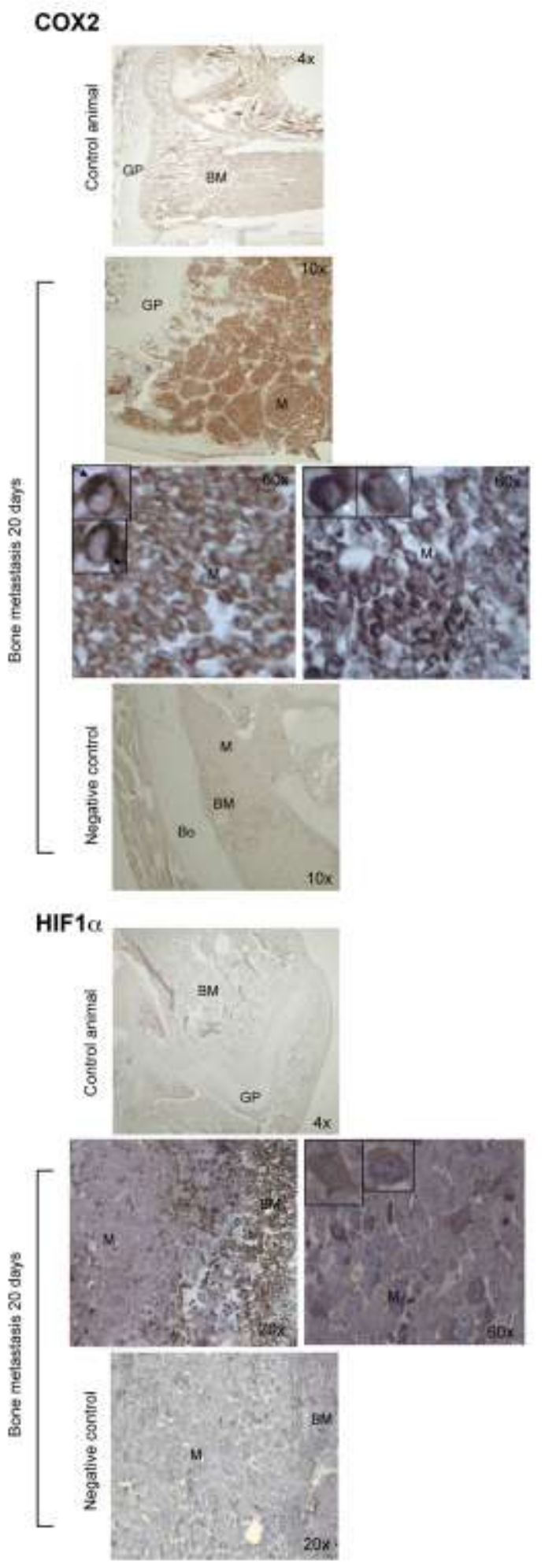
a

Patient 1

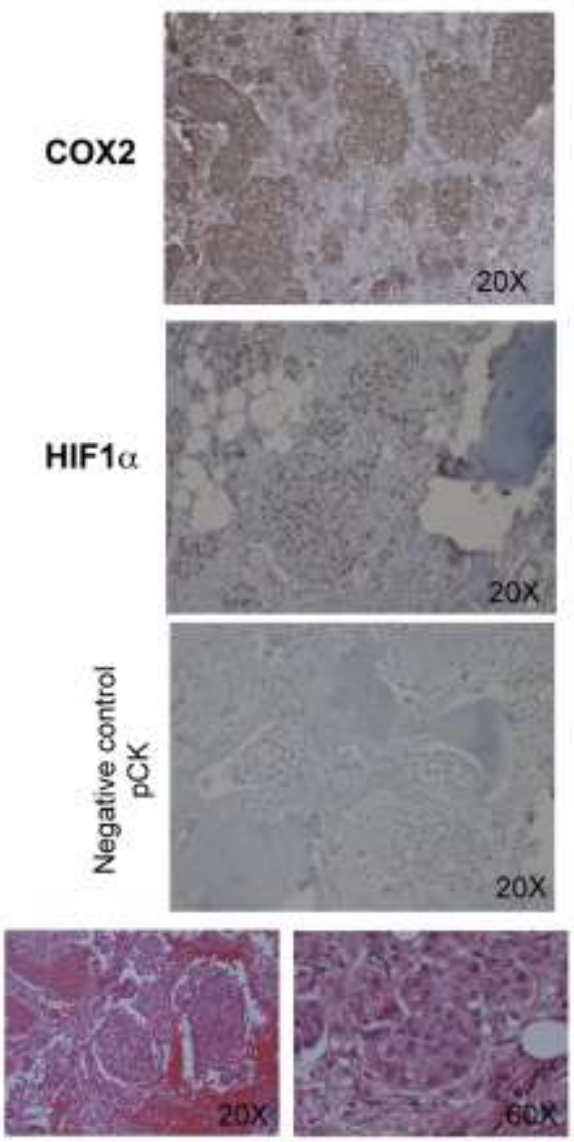

H\&E
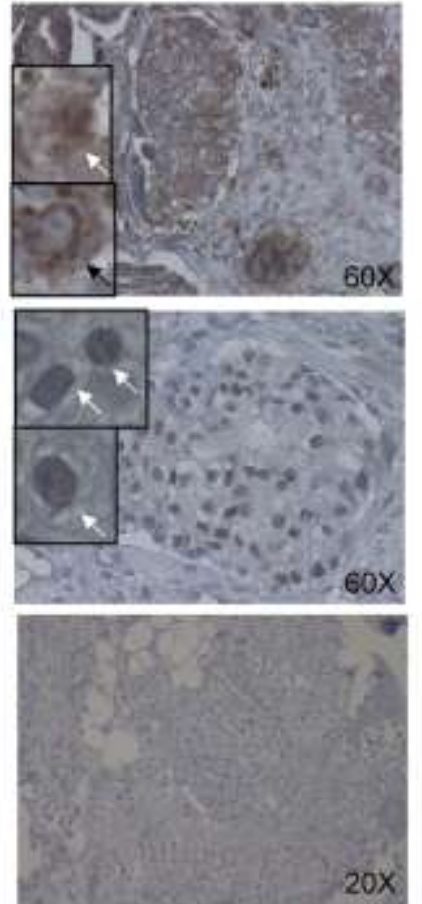

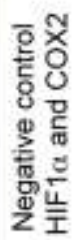

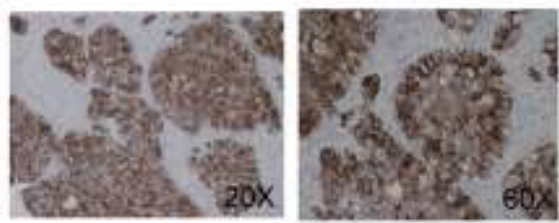

pCK
Patient 2

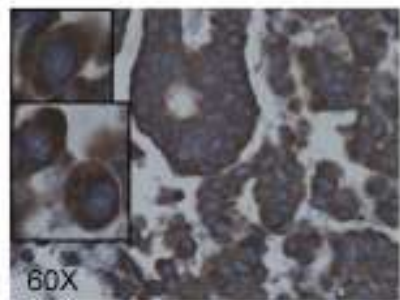

HIF1 $\alpha$
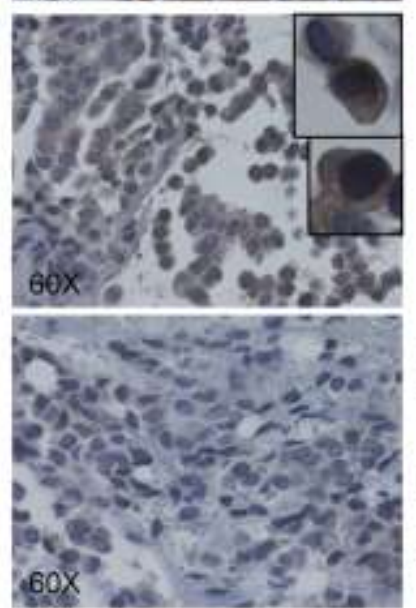

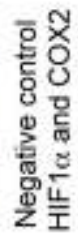

b

\begin{tabular}{|ccccc|}
\hline \multicolumn{4}{c}{ COX-2 } & \multicolumn{2}{c|}{ HIF-1 $\alpha$} \\
\hline & \multicolumn{2}{c|}{ localization and expression } & \multicolumn{2}{c|}{ localization and expression } \\
\hline Patient & nuclei & cytosol & nuclei & cytosol \\
\hline 1 & ++ & ++ & +++ & - \\
2 & ++ & +++ & +++ & + \\
3 & +++ & +++ & +++ & + \\
4 & + & ++ & ++ & + \\
5 & ++ & ++ & ++ & + \\
6 & +++ & +++ & ++ & - \\
7 & + & + & +++ & + \\
8 & ++ & +++ & +++ & - \\
9 & + & ++ & ++ & - \\
10 & ++ & ++ & ++ & + \\
\hline
\end{tabular}


a

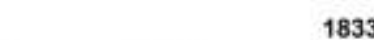

$\cos 2$

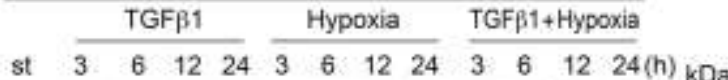

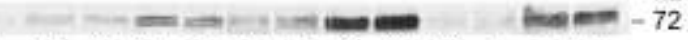

$\begin{array}{lllllllllllll}1 \times & 1.5 x & 1.6 x & 6.1 \times & 4.8 x & 2.2 x & 2.8 x & 13 x & 14 x & 0.8 x & 1 \times & 6.1 \times & 72 x\end{array}$

vinculin - - - - - - - - - - - - - 105

\section{MDA-MB231}

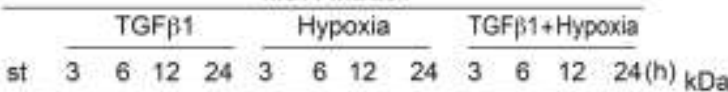

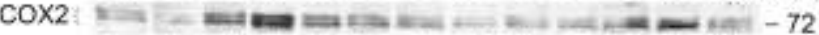

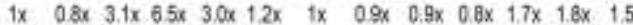

vinculin - - - - - - - - - - - - - - - - - - - - - -
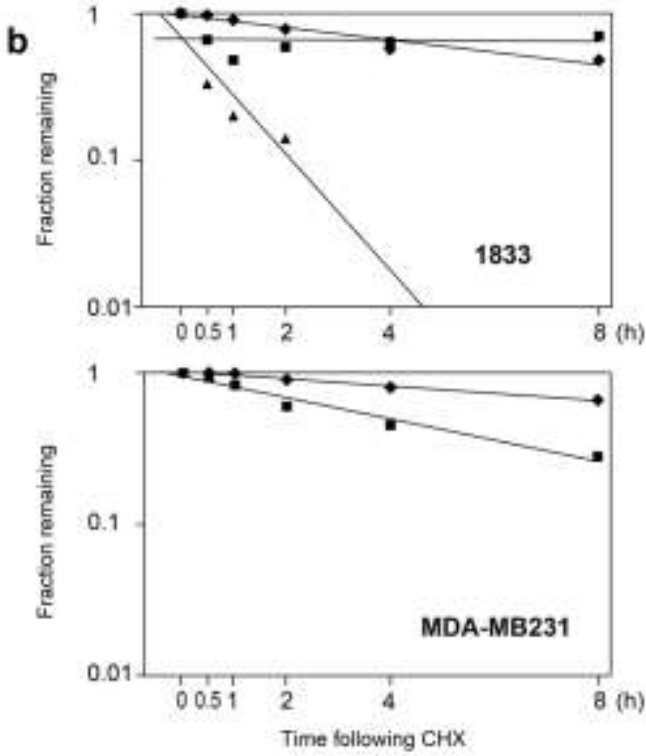

Hypoxia+

C

1833

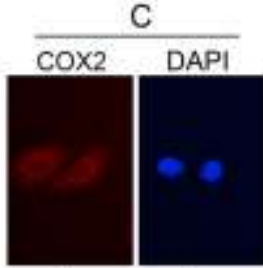

Hypoxia

\begin{tabular}{cc}
$\mathrm{CH} \times 2 \mathrm{~h}$ & $\mathrm{CHX} 4 \mathrm{~h}$ \\
\hline $\mathrm{DAPl}$ & $\mathrm{CO} \times 2$
\end{tabular}

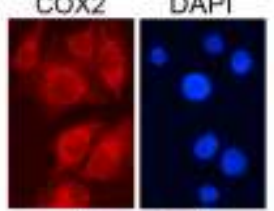

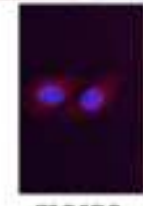

merge

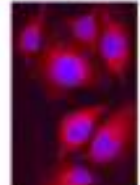

merge
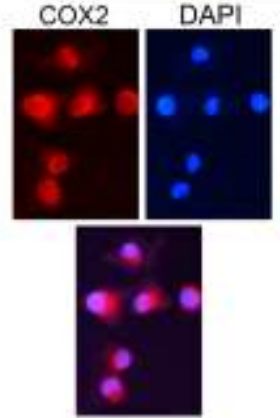

merge
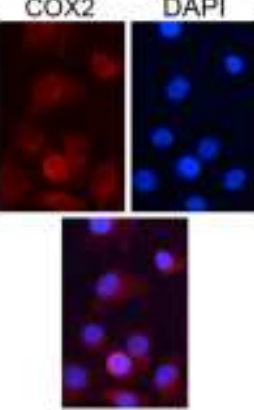

merge

d

1833

MDA-MB231

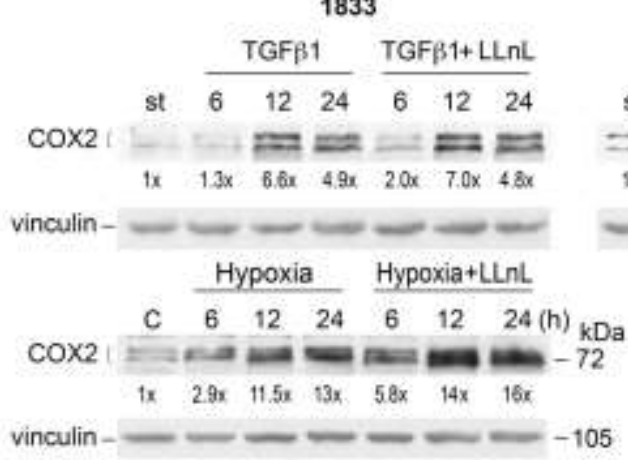



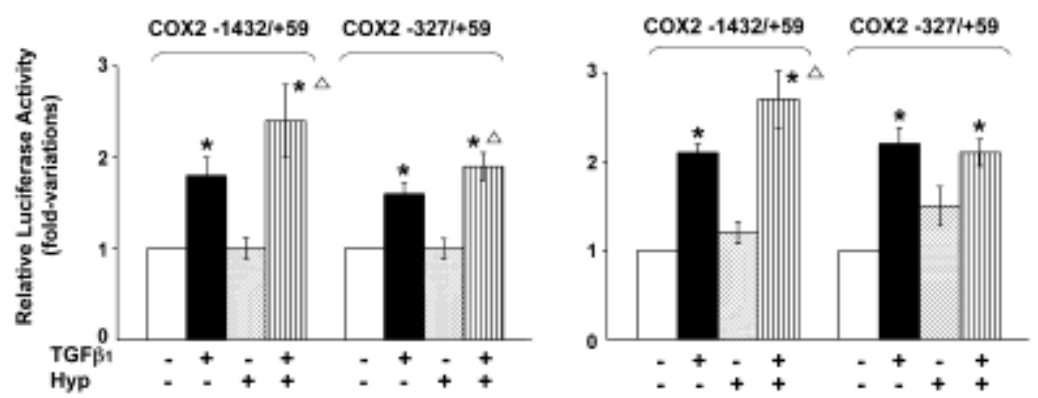

b

1833

MDA-MB231

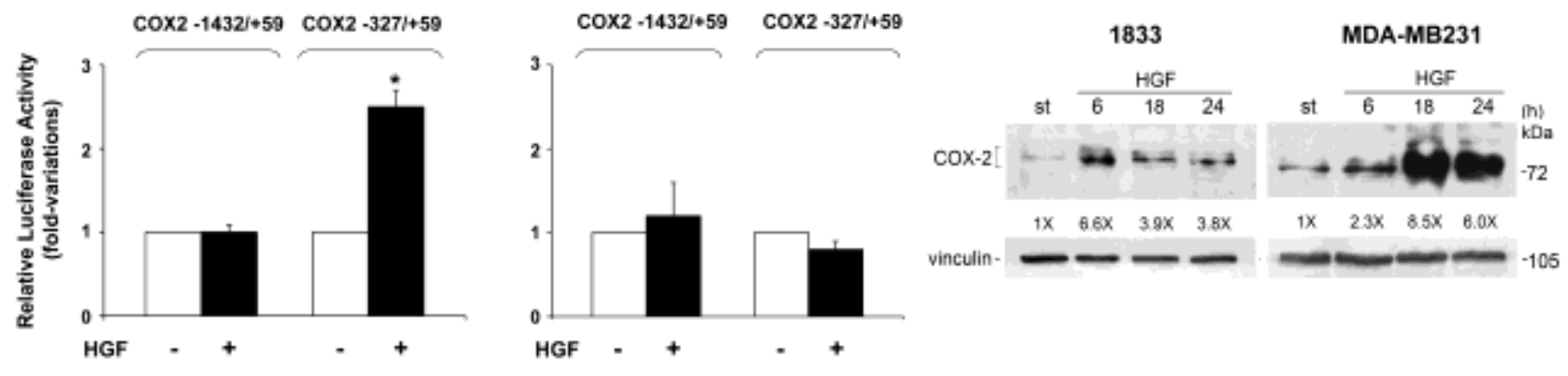

C

\begin{tabular}{|c|c|c|c|}
\hline \multicolumn{4}{|c|}{ TGFB 1 (pg/mg protein) } \\
\hline & C & Hypoxia & Fold-increase \\
\hline 1833 & $64.5 \pm 7.1$ & $305.9 \pm 39.8$ & $4.7^{* *}$ \\
\hline MDA-MB231 & $176.1 \pm 20.1$ & $375.7 \pm 41.5$ & $2.0^{*}$ \\
\hline
\end{tabular}

\begin{tabular}{|c|c|c|c|}
\hline \multicolumn{4}{|c|}{ HGF (pg/mg protein) } \\
\hline & C & Hypoxia & Fold-increase \\
\hline 1833 & $21.6 \pm 0.2$ & $39.3 \pm 2.9$ & $1.8{ }^{\star}$ \\
\hline MDA-MB231 & $22.5 \pm 0.2$ & $21.1 \pm 2.5$ & 0 \\
\hline
\end{tabular}

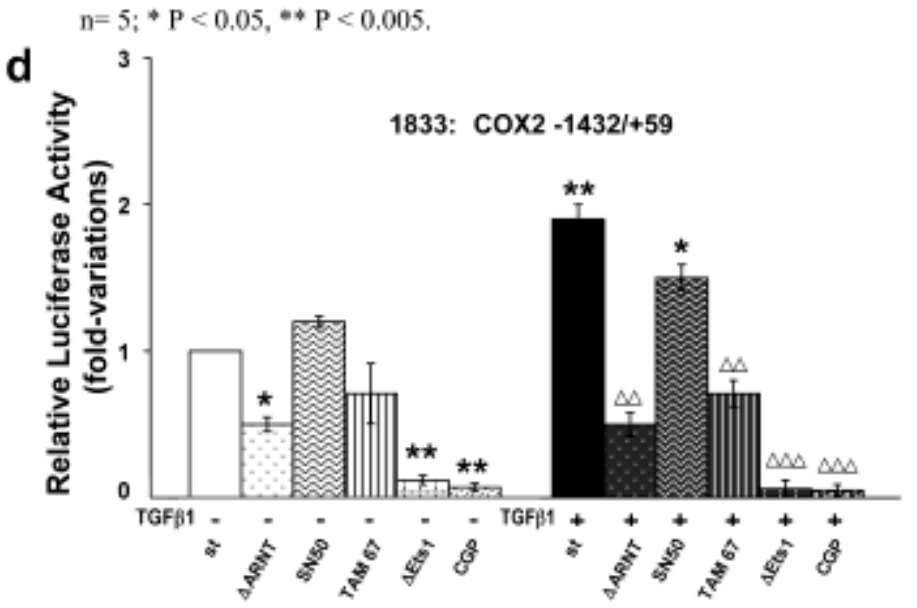

$\mathrm{n}=5 ; * \mathrm{P}<0.05$

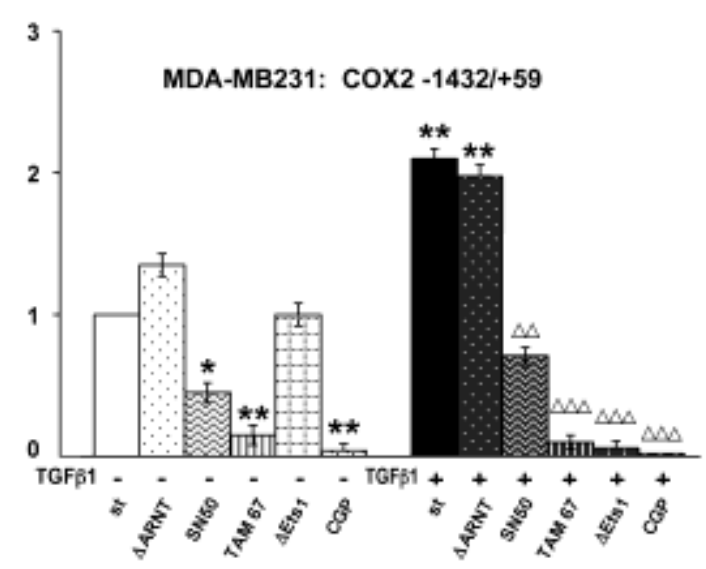

1833: $\operatorname{cox} 2-327 /+59$

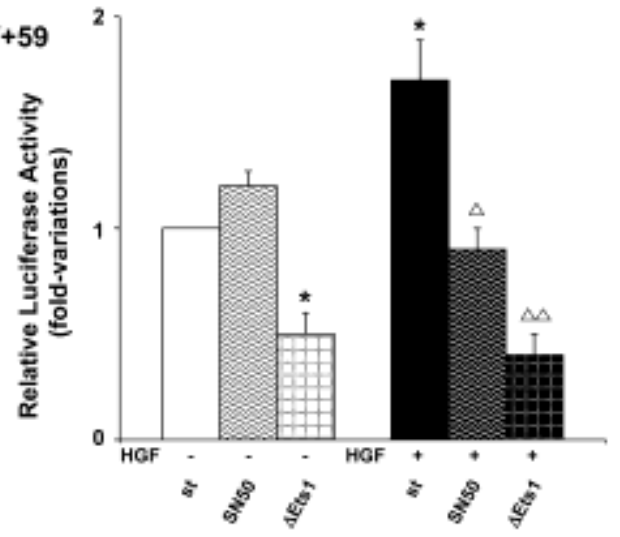


a

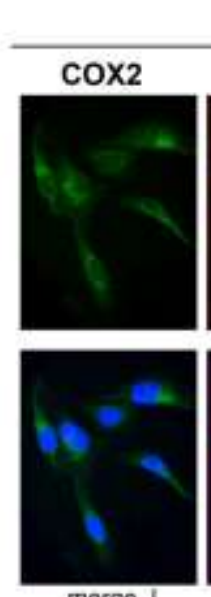

merge I st
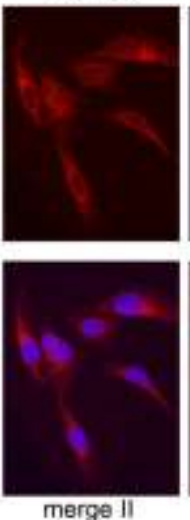

DAPI
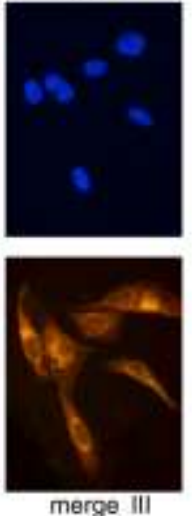

merge III
1833

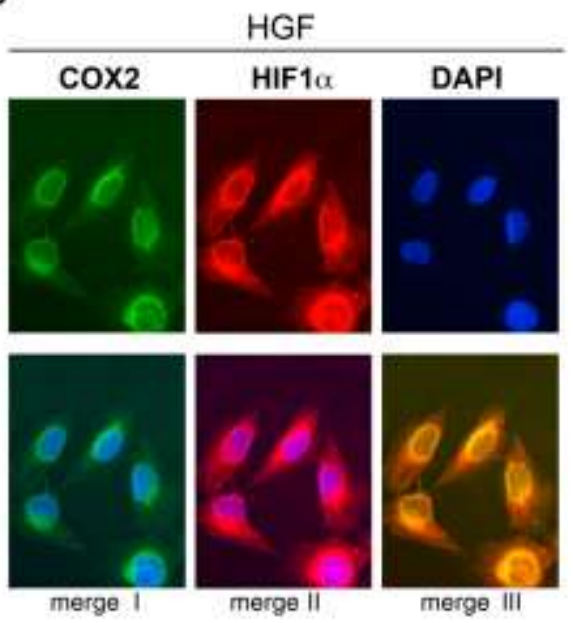

HGF+LLnL

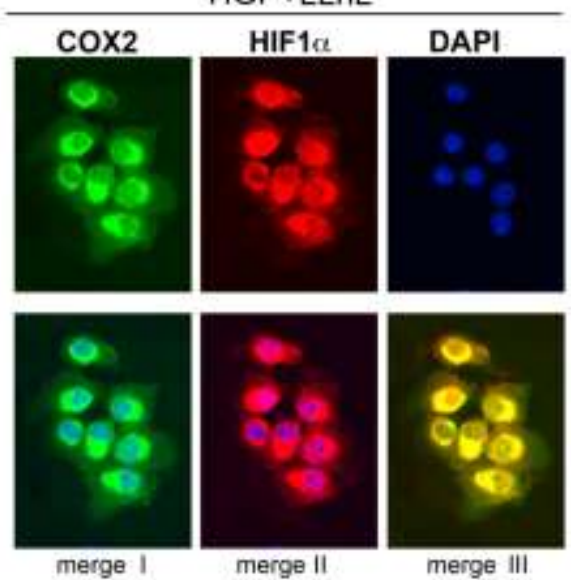

C

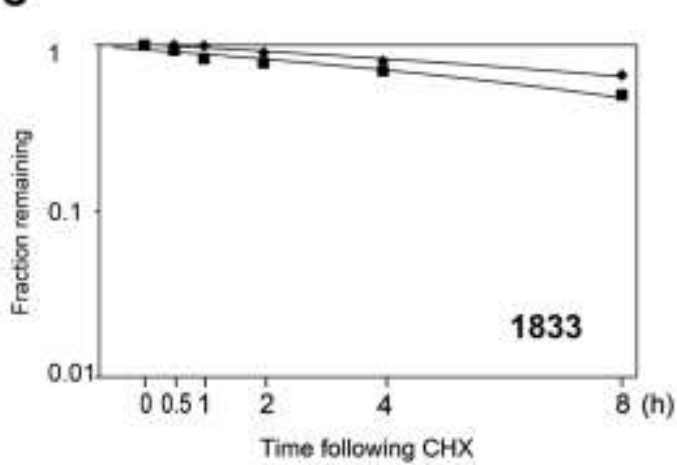

d

1833

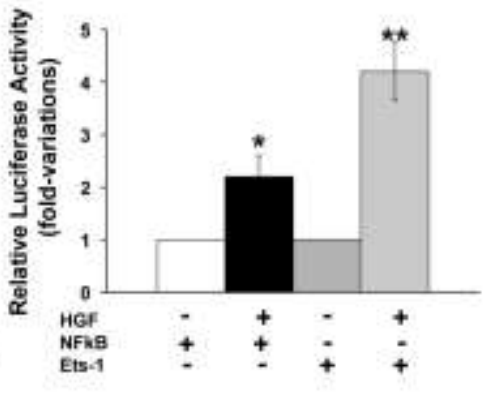


a

Nuclear extracts

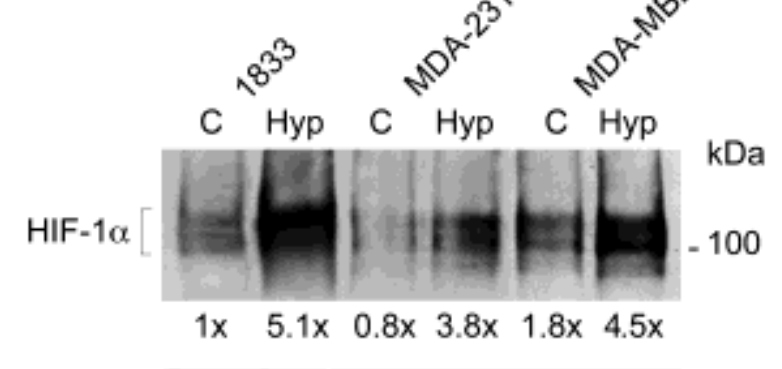

B23-
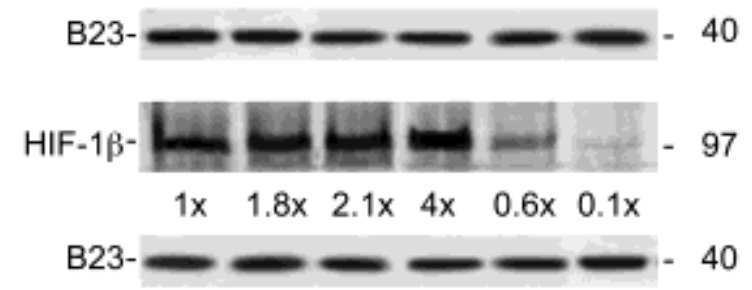

c
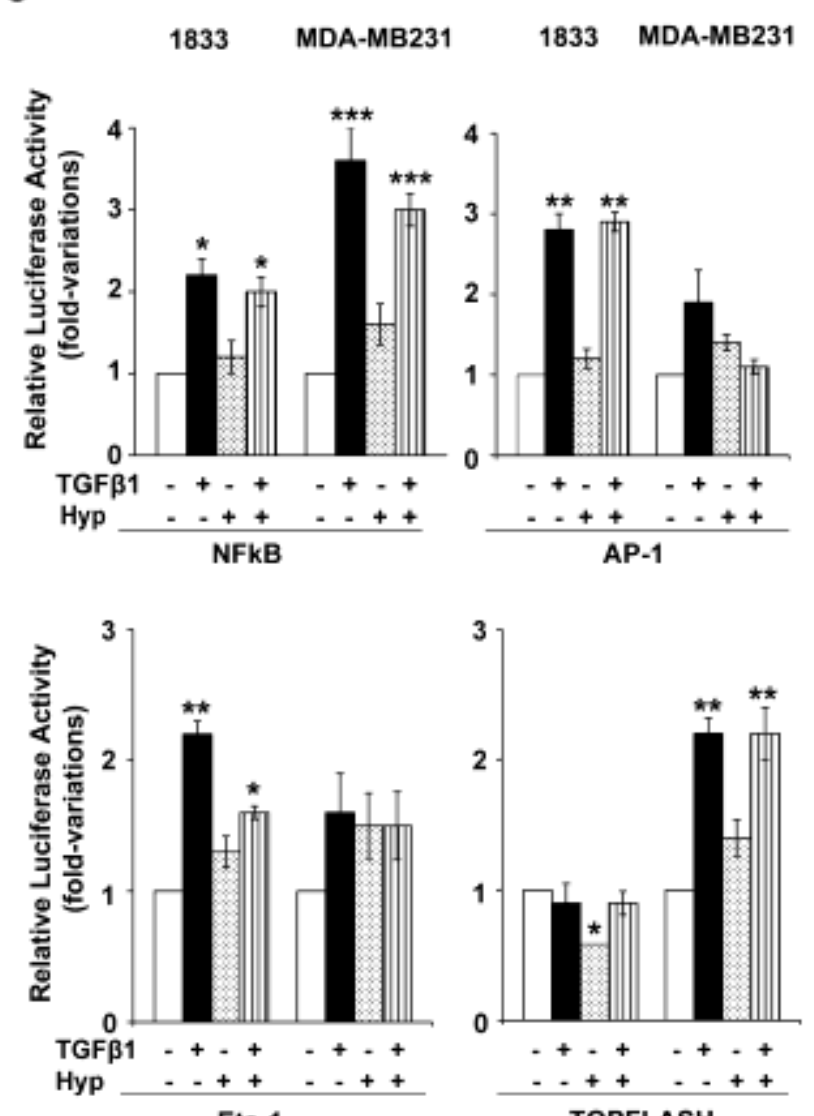

Ets-1 b
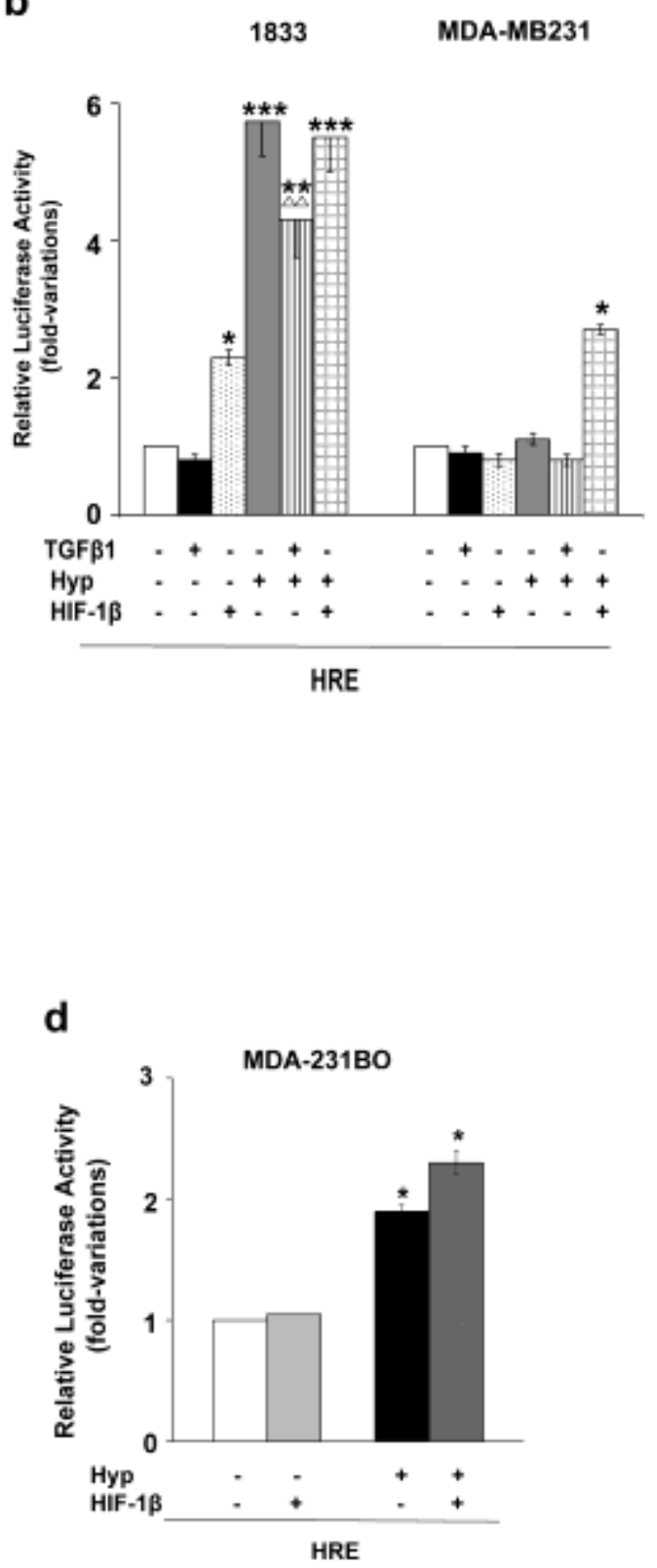
a

1833

st $\begin{gathered}\text { Nuclear extracts } \\ \text { sGF } \beta 1\end{gathered}$

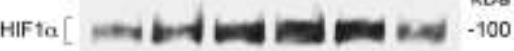

$\begin{array}{llllll}1 x & 3.1 x & 41 . & 45 x & 4.4 x & 2.3 x\end{array}$

B23- $=0-40$

MDA-MB231

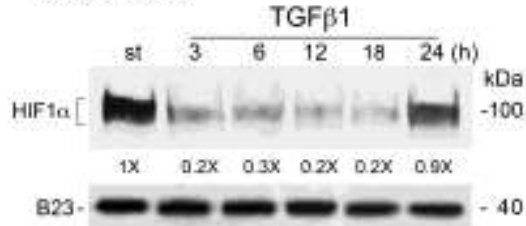

b

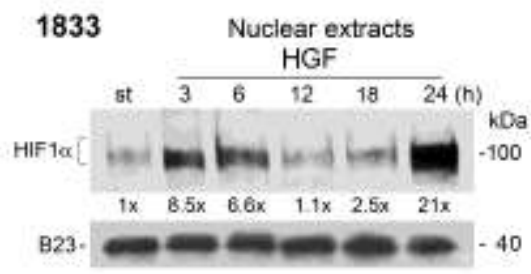

MDA-MB231

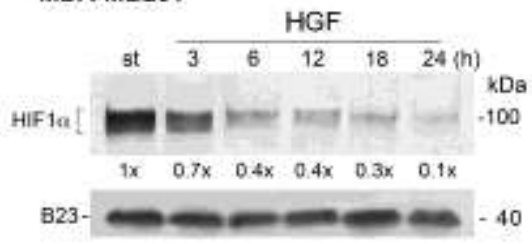

1833

Ets1Lue HRELuc TOPFLASHLue

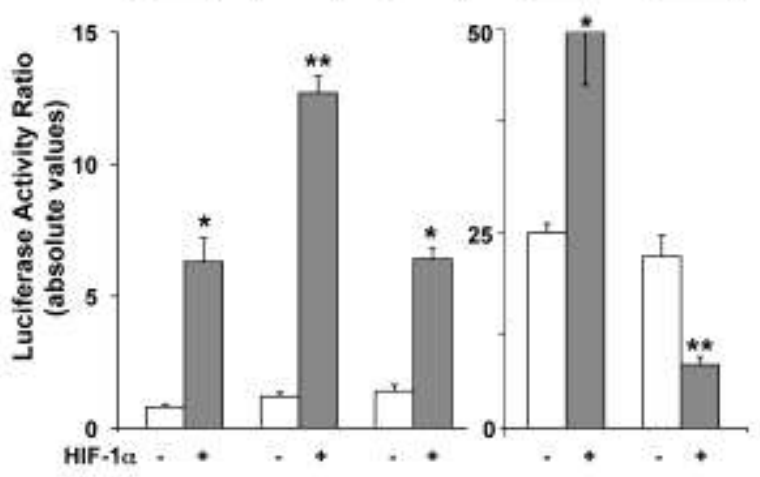


a 1833 Total extracts
HGF- - - - - - - $1 \times 2.3 \times 1.4 \times 1.6 \times 1.8 \times 3.6 \times 2.8 \times 2.2 \times 4.4 \times 3.3 \times$

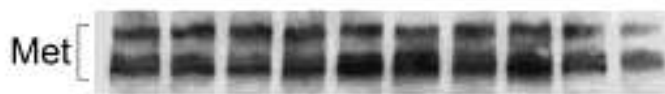

$1 \times \quad 1.3 \times 1.2 \times 1.3 \times 1.8 \times 1.7 \times 1.3 \times 1.7 \times 1.1 \times 0.9 \times$

VEGF- 2000 $1 \times 1.3 \times 1.7 \times 1.2 \times 1.5 \times 1.6 \times 1.2 \times 1.1 \times 1.2 \times 0.8 \times$ vinculin-
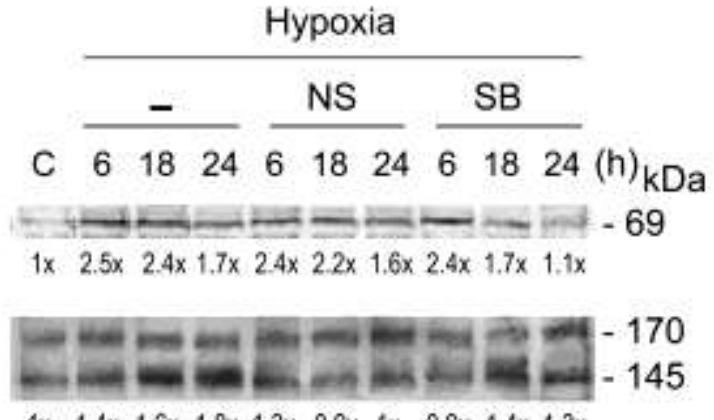

$1 \times \quad 1.4 \times 1.6 \times 1.8 \times 1.3 \times \quad 0.9 \times$ ix $\quad 0.9 \times 1.4 \times 1.3 \times$

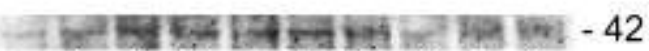

$1 \times \quad 3 \times \quad 4.2 \times 5.9 \times 5.1 \times 5.4 \times 5.2 \times 1.2 \times 1.7 \times \quad 2 x$ $-105$

b

$\frac{\text { TGFB1 }}{\frac{-}{61824} \frac{\text { NS }}{61824} \frac{\text { SB }}{61824}}$

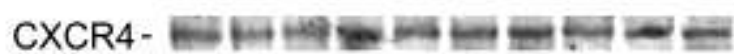
$\begin{array}{llllllllll}1 \mathrm{x} & 1 \mathrm{x} & 1 \mathrm{x} & 1.2 \mathrm{x} & 1 \mathrm{x} & 1 \mathrm{x} & 1.2 \mathrm{x} & 1 \mathrm{x} & 1.1 \mathrm{x} & 1.1 \mathrm{x}\end{array}$

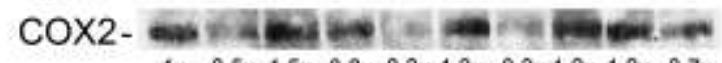
$\begin{array}{llllllll}1 \times & 0.5 \times & 1.5 \times & 0.8 \times & 0.3 \times 1.3 \times & 0.3 \times 1.2 \times 1.2 \times & 0.7 \times\end{array}$

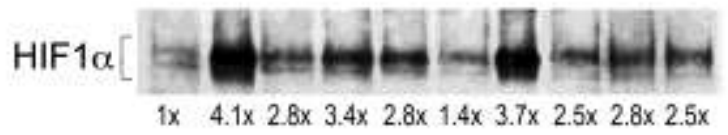

B23- ix $4.1 \times 2.8 \times 3.4 \times 2.8 \times 1.4 \times 3.7 \times 2.5 \times 2.8 \times 2.5 \times$

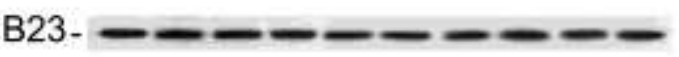

Hypoxia

C $\frac{-}{61824} \frac{\mathrm{NS}}{61824} \frac{\mathrm{SB}}{61824(\mathrm{~h})_{\mathrm{kDa}}}$

vexd :

1. $0.5 \times \quad 0.2 \times \quad 0.2 \times \quad 0.6 \times 0.4 \times 0.4 \times 0.5 \times 0.6 \times 0.8 \times$

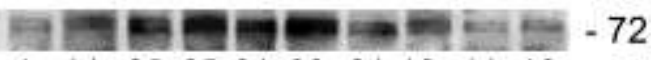

$1 \times \quad 1.4 \times \quad 2.5 \times 3.7 \times 3.1 \times 6.6 \times 2.1 \times 1.8 \times 1.1 \times 1.3 \times$

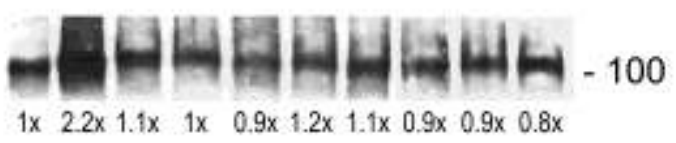

$\begin{array}{lllllllllllll}1 \times & 2.2 \times & 1.1 \times & 1 \times & 0.9 \times & 1.2 \times & 1.1 \times & 0.9 \times & 0.9 \times & 0.8 \times\end{array}$

$-40$ 


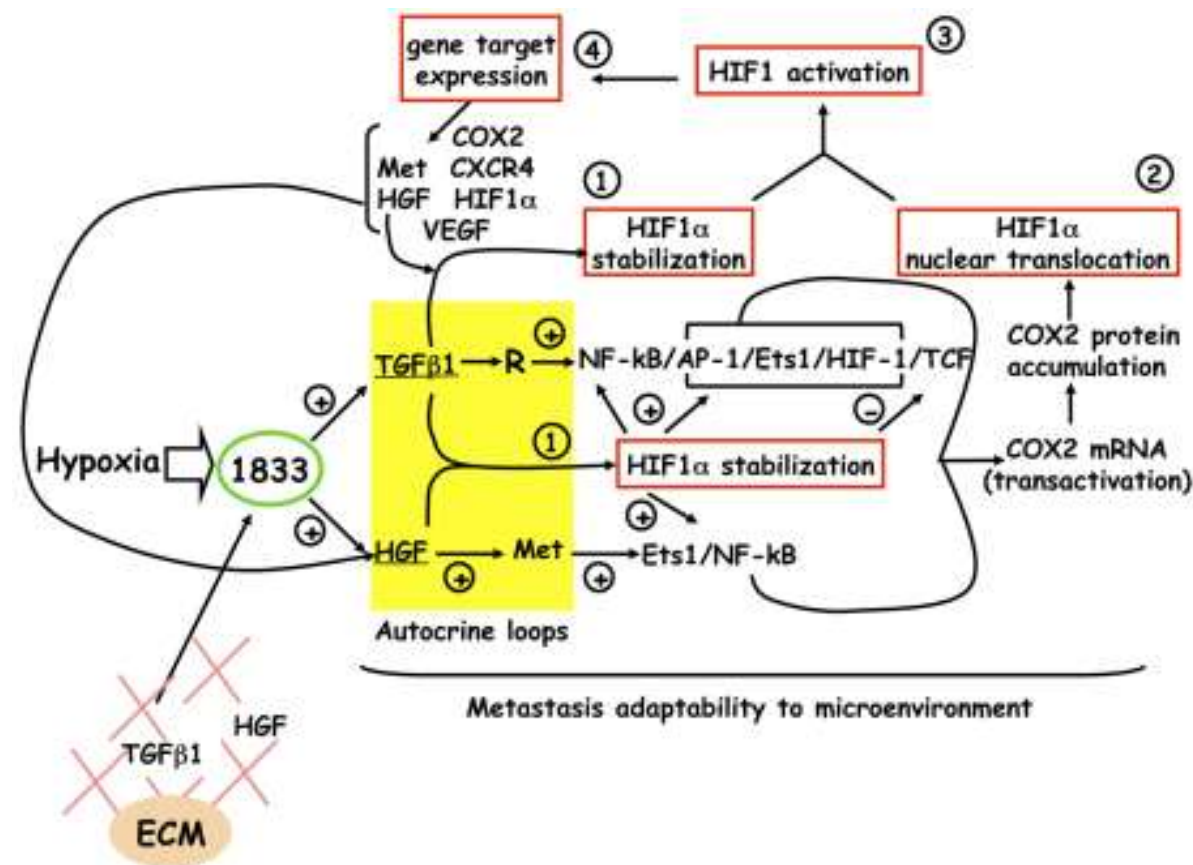




\section{Copyright Transfer Statement}

\section{BREAST CANCER RESEARCH AND TREATMENT}

The copyright to this article is transterred to Springer (respective to owner if other than Springer and for U.S. government employees; to the extent transferabie) effective if and when the auticle is accepted for publication. The copyright transter covers the excusive right to reprodtuce and distribute the articie, inciuding reprints, tranelations, photographic reproductions, microform, electronic form (offline, online) or any other reproductions of similer nature.

An author may aeli-erchive an author-created version of hisiher article on hlshther own website and hisher institution's repository, including hisher tinal version; however he/ she may not use the pubitshor's PDF version which is posted on www.epringerink.com, Furthermore, the author may only post hisher version provided acknowledgement is given to the original source of publication and a link is inserted to the publlshed article on Springer's wobsite, The link must be accompaniad by the following text: "The original publlcation is available at www.sprkngotink.com".

Please use the appropriate DOI for the arsicle (go to the Linking Options ho life articie, then to OpenURL and use the linik with the DOi). Articles disseminated via wuw.springartink.com ave indexed, abstracted, end referenced by many abstrecting ano information services, blblograohic networks, subsccription agencies, library networks, and consortia.

The authox warrants that this contribution is original and that he/she has full power to make this grant. The author signs tor and aocopts responsibility for releasing this material on behtrall of any and ail co-authors.

\section{Finanelat Disctosure/Confliet of interest Statement}

1, the undersigned author, certify that the authors of the Article have no commerclat associations \{e.gin, oonsultancies, stock ownership, equity interssts, patent-jicensing arrangements, otc.\} 1hat might pose a contllet of interest in connection with the submilted arlicle, except as disclosed on ㅍ separate attachment. All furvding sources supporting the work and all instifutional or corporate ulfilizations of the authors are acknowledged in a foolnote.

․ Check hese if a seperato attachment is enclosed.

Atrer submission of this agreament slgned by the corresponding author changes of authorship or In the orrier of the authorg liated wilf not be accepted by Springor.

\section{Itthe of article:}

Buthor(s):

Autrot's signature:

Date: 